\title{
Informed Consent in HIV Prevention Trials: Report of an International Workshop
}

C. Elizabeth McGrory

Barbara Friedland

Population Council

Cynthia Woodsong

Kathleen M. MacQueen

Follow this and additional works at: https://knowledgecommons.popcouncil.org/departments_sbsr-hiv

Part of the Health Services Research Commons, Immune System Diseases Commons, International Public Health Commons, Medicine and Health Commons, Public Health Education and Promotion Commons, Quantitative, Qualitative, Comparative, and Historical Methodologies Commons, and the Virus Diseases Commons How does access to this work benefit you? Let us know!

\section{Recommended Citation}

McGrory, C. Elizabeth, Barbara Friedland, Cynthia Woodsong, and Kathleen M. MacQueen. 2006. Informed Consent in HIV Prevention Trials: Report of an International Workshop. New York: Population Council.

This Report is brought to you for free and open access by the Population Council. 


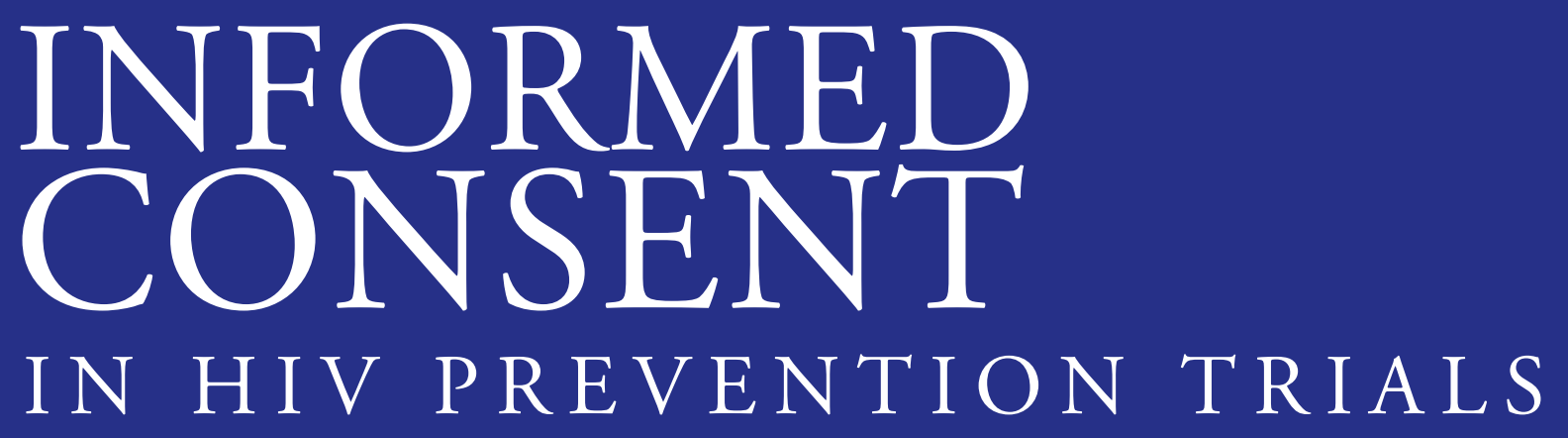

REPORT OF AN INTERNATIONAL WORKSHOP

by C. Elizabeth McGrory, Barbara A. Friedland,
Cynthia Woodsong, Kathleen M. MacQueen

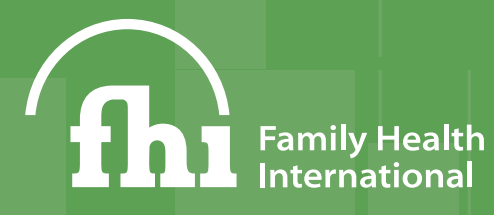




\section{INFORMED CONSENT IN HIV PREVENTION TRIALS}

REPORT OF AN INTERNATIONAL WORKSHOP

by

C. Elizabeth McGrory, Barbara A. Friedland, Cynthia Woodsong, and Kathleen M. MacQueen

16-18 May 2005

New York City

Cohosted by Population Council Family Health International 


\section{Population Council}

The Population Council is an international, nonprofit, nongovernmental organization that seeks to improve the well-being and reproductive health of current and future generations around the world and to help achieve a humane, equitable, and sustainable balance between people and resources. The Council conducts biomedical, social science, and public health research and helps build research capacities in developing countries. Established in 1952, the Council is governed by an international board of trustees. Its New York headquarters supports a global network of regional and country offices.

One Dag Hammarskjold Plaza

New York, NY 10017 USA

Telephone: (212) 339-0500

Fax: (212) 755-6052

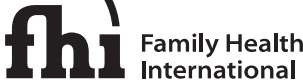

Family Health International (FHI) is dedicated to improving lives, knowledge, and understanding worldwide through a highly diversified program of research, education, and services in family health and HIV/AIDS prevention and care. Since its inception in 1971, FHI has formed partnerships with national governments and local communities in countries throughout the developing world to support lasting improvements in the health of individuals and the effectiveness of entire health systems.

Post Office Box 13950

Research Triangle Park, NC 27709 USA

Telephone: (919) 544-7040

Fax: (919) 544-7261
2101 Wilson Boulevard, Suite 700

Arlington, VA 22201 USA

Telephone: (703) 516-9779

Fax: (703) 516-9781

\section{USAID}

This publication was made possible through support provided by the Office of Population and Reproductive Health, Bureau for Global Health, USAID, under the terms of Award No. GPO-A00-04-00019. The opinions expressed herein are those of the authors and do not necessarily reflect the views of USAID.

Copyright (C) 2006 The Population Council, Inc.

Any part of this report may be copied or adapted to meet local needs without permission from the Population Council, provided that the parts copied are distributed freely or at cost (not for profit) and that the source is identified. Any commercial reproduction requires prior permission from the Population Council. The Population Council would appreciate receiving a copy of any materials in which the text is used.

http://www.popcouncil.org/pdfs/ICWorkshop.pdf 


\section{Table of Contents}

Acknowledgments . . . . . . . . . . . . . . . . . . . . .

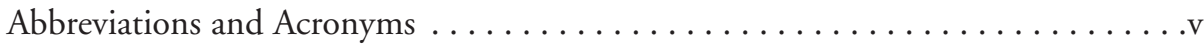

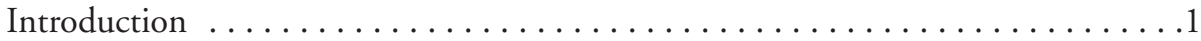

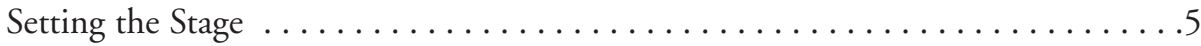

Factors Influencing Informed Consent $\ldots \ldots \ldots \ldots \ldots \ldots \ldots \ldots$

Community Involvement and Informed Consent $\ldots \ldots \ldots \ldots \ldots \ldots \ldots$

Tools To Enhance the Informed Consent Process $\ldots \ldots \ldots \ldots \ldots \ldots \ldots$

Assessing Comprehension . . . . . . . . . . . . . . . . . . . . . . . . . . 29

Monitoring and Evaluation of the Informed Consent Process . . . . . . . . . . 35

Conclusion and Recommendations ...................... 37

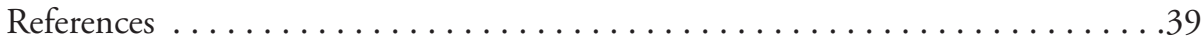

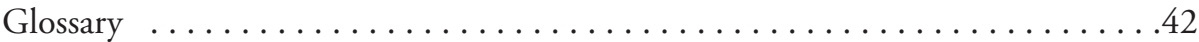

Appendices

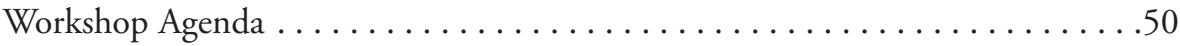

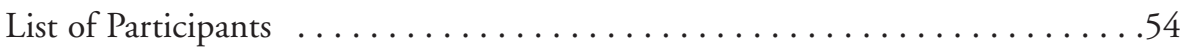




\section{Acknowledgments}

The workshop on informed consent in HIV prevention trials was conceptualized and planned by a committee comprised of Barbara Friedland, Martha Brady, and Hillary Bracken (Population Council); Kathleen MacQueen (Family Health International); Cynthia Woodsong (Research Triangle Institute), and Elizabeth McGrory (consultant).

The authors would like to thank the workshop presenters for their high-caliber presentations and all workshop participants for their contribution to an engaging, productive discussion. We are grateful to Martha Brady, Anna Forbes, Annie Kee and Leigh Peterson for their thoughtful comments on previous drafts. Thanks to
Lauren Katz, Elaine Baur, and Maria Alevrontas for their assistance and good humor in organizing the workshop, and to Virginia Kallianes for her assistance in preparing grant proposals, organizing the meeting details, and helping with the production of this report.

Major support for the workshop was provided by the United States Agency for International Development (USAID) and the International Partnership for Microbicides (IPM). Additional funding was provided by the William and Flora Hewlett Foundation and the National Institute of Child Health and Human Development (NICHD) of the National Institutes of Health (NIH). 


\section{Abbreviations and Acronyms}

ACASI Audio computer-assisted selfinterviewing

AIDS Acquired immunodeficiency syndrome

BOTUSA Collaboration of the Botswana

Project Ministry of Health and US

Centers for Disease Control and Prevention

$\mathrm{CAB}$ Community Advisory Board

CAG Community Advisory Group

CDC (US) Centers for Disease Control and Prevention

CFR (US) Code of Federal Regulations

DFID (UK) Department for International Development

FAQ Frequently asked questions

FDA (US) Food and Drug Administration

FHI Family Health International

GCP Good clinical practice

HIV Human immunodeficiency virus

HIVNET HIV Network for Prevention Trials

HPTN HIV Prevention Trials Network

HPV Human papillomavirus

HSV-2 Herpes simplex virus type 2

$\mathrm{ICH}$ International Committee on Harmonisation of Technical

Requirements for Registration of Pharmaceuticals for Human Use

IDU Injecting drug user

IEC Information, education, and communication
IRB Institutional review board

MCC Medicines Control Council (of South Africa)

MDP (UK) Microbicides Development Programme

MEDUNSA Medical University of Southern Africa (now part of the University of Limpopo)

MIRA Methods of Improving Reproductive Health in Africa

MRC Medical Research Council (of the UK or South Africa)

NIAID (US) National Institute of Allergy and Infectious Diseases

NICHD (US) National Institute of Child Health and Human Development

NIH (US) National Institutes of Health

OHRP (US) Office of Human Research Protections

PEP Postexposure prophylaxis

PI Principal investigator

PREP Pre-exposure prophylaxis

RTI Research Triangle Institute

SOP Standard operating procedure

STI Sexually transmitted infection

UCT University of Cape Town

UNAIDS Joint United Nations

Programme on HIV/AIDS

USAID United States Agency for International Development

VCT Voluntary counseling and testing 


\section{Introduction}

In the dynamic and rapidly evolving arena of HIV/AIDS research, informed consent is recognized as a critical dimension of making ethics operational. Informed consent has been identified as a priority area in a wide range of consultations and meetings on ethics and clinical trials, including Practical and Ethical Dilemmas in the Clinical Testing of Microbicides (Heise 1998); Rethinking the Ethical Roadmap for Clinical Testing of Microbicides (Global Campaign for Microbicides 2005); Stakeholder Consultation to Address Issues Related to Tenofovir Prophylaxis Research (International AIDS Society 2005); and Creating Effective Partnerships for HIV Prevention Trials (UNAIDS 2006). Ensuring informed consent in clinical trials is a shared goal among researchers and activists seeking to design and implement technically and politically complex research in a manner that respects the priorities and rights of trial participants and communities.

Although ensuring informed consent and voluntary participation is one of the most complicated aspects of conducting any clinical trial, HIV prevention trials, many of which are being conducted in resource-poor settings, pose greater ethical and practical challenges than do other trials. First, HIV/AIDS remains highly stigmatized in many of the settings where clinical trials of prevention technologies are being conducted. Second, such trials involve other sensitive issues, including sexuality and gender-based power dynamics. Finally, because large-scale efficacy trials must be conducted in areas with a high incidence of HIV, researchers must recruit healthy volunteers who often are economically and socially vulnerable and at substantial risk of HIV infection.

An inherent challenge for the informed consent process in HIV prevention trials is ensuring that participants understand that trial participation will neither protect them from nor increase their exposure to HIV. Researchers must reinforce the unknown efficacy of the test product so that participants do not feel a false sense of protection, or "therapeutic misconception," which could lead to increased risk behavior (such as reducing condom use or increasing numbers of partners).

There is extensive literature concerning the theoretical considerations of informed consent and its role in ethical research. Many studies have been conducted to assess specific aspects of informed consent, such as comprehension, readability, and presentation of information. However, the majority of these studies involved treatment for people with lifethreatening diseases such as cancer, and few have been conducted in developing countries.

The practical aspects of informed consent for clinical trials of prevention technologies have received far less attention; only a few studies have addressed informed consent in contraceptive and (non-HIV) vaccine trials (Rivera et al. 1992; Préziosi et al. 1997; Fortney 1999; Leach et al. 1999). As the number of HIV prevention trials increases, several researchers have described the challenges and the importance of implementing an effective informed consent process, highlighting the need for information on the practical aspects of effectively implementing informed consent (Ramjee et al. 2000; Kilmarx et al. 2001; Coletti et al. 2003; Mariner 2003). 
Informed consent is sometimes regarded by both volunteers and study staff as merely a bureaucratic requirement for enrollment in order to comply with legal and regulatory codes. Informed consent takes place as a oneway communication: a trial volunteer reads a complicated legal form, and his or her signature or mark on the form symbolizes "consent" to enroll in the trial. It is a one-time event that is rarely revisited once the form is signed and filed. Since many researchers, trial sponsors and communities consider this approach to be inadequate for achieving (and maintaining) truly informed consent, the HIV prevention field has been moving away from this more legalistic and mechanistic approach centered on the form and the signature.

An emerging view positions informed consent as an agreement between the researcher and the participant that should be based on dialogue and reinforced through an ongoing process throughout the trial. A number of HIV prevention trials are investing in and experimenting with a range of dynamic and creative approaches to ensuring informed consent. These include providing one-on-one counseling and support with well-trained staff; developing and deploying supplemental tools such as videos and booklets; systematically assessing comprehension; and actively engaging communities as partners in the informed consent process.

A growing number of trials of HIV prevention technologies are underway and in the planning phases. These trials provide an opportunity to evaluate and learn from practical experience with informed consent processes. The rapid growth and evolution of the field also underscores the importance of identifying successful approaches to informed consent in HIV prevention trials that can be used and adapted more widely.

Recognizing this opportunity and need, the Population Council and Family Health International cohosted an international workshop on 16-18 May 2005, focusing specifically on the informed consent process in HIV prevention trials. To facilitate learning among participants with diverse backgrounds and approaches, the meeting blended experience from ongoing and planned clinical trials with theoretical underpinnings in areas like risk perception, adult learning theory, and bioethics. The workshop drew together more than 70 participants from 11 countries and varied backgrounds: representatives from research institutions, trial sponsors and advocacy groups; donors; principal investigators and clinic staff; social scientists; and experts in related fields. A third day was targeted to a subset of participants directly involved with developing materials and implementing the informed consent process. (See Table 1 on page 4 for a complete list of the trials represented.)

Workshop participants enjoyed a rich and lively set of presentations and discussions on key practical and conceptual issues concerning informed consent. Many participants shared their experiences with the dynamic and sometimes frustrating processes of developing materials, designing and implementing new procedures, conducting assessments, and advocating for the importance of attention to informed consent within complex trial and community contexts.

This report captures the main topics discussed at the workshop. The first section reviews the historical and regulatory foundations of informed consent. The next section 
touches on several among myriad factors that influence informed consent: contextual issues; risk perception and decisionmaking; compensation; and autonomy, especially with regard to women's participation in clinical trials. A related discussion follows concerning the central role that communities can play in informing research processes as well as influencing individual decisions. The main section of the report explores a range of practical issues related to developing and using tools to enhance the informed consent process and is followed by a discussion of how best to assess the effect that all these efforts have on participants' comprehension. These sections, in particular, incorporate examples from completed and existing clinical trials to illustrate concrete opportunities and challenges associ- ated with this process. The final section reviews results and strategies for evaluating informed consent processes. The report ends with recommendations for further consultation and research on this issue.

The workshop underscored the dynamic and creative way that clinical trial sponsors and investigators, clinic staff, social science researchers, donors, and communities are approaching the challenge of informed consent in these complex and critical trials.

Participants left the workshop charged with new ideas and approaches to bring to their work and committed to identifying opportunities for ongoing collaboration. Addressing these compelling issues is central to the ethical and practical implementation of this critically important research. 
Table 1 Trials represented at the workshop on informed consent in HIV prevention trials, 16-18 May 2006

\begin{tabular}{llll}
\hline Product & Trial description & Developer/sponsor & \\
& & Sites
\end{tabular}

\section{BARRIER METHOD}

Latex diaphragm

Latex diaphragm to prevent HIV

acquisition among women/

"female-controlled" physical

Janssen Ortho MacNeil

Pharmaceuticals/University

Durban and Johannesburg,

barrier of the cervix ("Methods

of California at San Francisco/

South Africa

for Improving Reproductive

Bill \& Melinda Gates

Health in Africa/MIRA")

\section{MICROBICIDES} Phase 1 safety and acceptability

Foundation

Harare, Zimbabwe

(HIVNET 009) study in low-risk women
BufferGel $^{\mathrm{TM}}$

ReProtect/Family Health Inter- Pune, India national (FHI)/Fred Hutchinson Cancer Research Center/ National Institute of Allergy and

\begin{tabular}{ll}
\hline BufferGel $\left.\right|^{\mathrm{TM}}$ and & Phase 2/2b safety and \\
PRO 2000 & effectiveness study \\
(HPTN 035) &
\end{tabular}
Indevus/ReProtect/NIAID Infectious Diseases (NIAID)

Chiang Mai, Thailand

Blantyre, Malawi

Harare, Zimbabwe

Blantyre and Lilongwe, Malawi

Hlabisa and Durban, South Africa

Philadelphia, United States

Lusaka, Zambia

Chitungwiza and Harare, Zimbabwe

\begin{tabular}{ll}
\hline Carraguard $^{\circledast}$ & $\begin{array}{l}\text { Phase } 3 \text { safety and efficacy trial } \\
\text { to prevent HIV seroconversion } \\
\text { in women }\end{array}$ \\
\hline Carraguard $^{\circledast}$ & $\begin{array}{l}\text { Phase 1 safety and acceptability } \\
\text { study in HIV-negative, mono- } \\
\text { gamous, low-risk couples (TUC) }\end{array}$
\end{tabular}

\begin{tabular}{|c|c|}
\hline $\begin{array}{l}\text { Cellulose sulfatel } \\
\text { CS }(6 \%)\end{array}$ & $\begin{array}{l}\text { Phase } 3 \text { randomized controlled } \\
\text { trial for safety and efficacy }\end{array}$ \\
\hline $\begin{array}{l}\text { PRO } 2000 \\
\text { (HPTN 047) }\end{array}$ & $\begin{array}{l}\text { Phase } 1 \text { safety and acceptability } \\
\text { study }\end{array}$ \\
\hline PRO 2000 & $\begin{array}{l}\text { Phase } 3 \text { trial to determine } \\
\text { efficacy and safety of two } \\
\text { concentrations }(0.5 \% \text { and } 2 \%) \\
\text { of PRO } 2000\end{array}$ \\
\hline
\end{tabular}

\begin{tabular}{lll}
\hline $\begin{array}{l}\text { Savvy } \\
(1.0 \%)\end{array}$ & $\begin{array}{l}\text { Phase } 3 \text { randomized controlled } \\
\text { study of safety and efficacy }\end{array}$ & $\begin{array}{l}\text { Biosyn/Cellegy/ Family Health } \\
\text { International (FHI)/USAID }\end{array}$ \\
\hline $\begin{array}{l}\text { Tenofovir gel (1\%) } \\
\text { (HPTN 055) }\end{array}$ & $\begin{array}{l}\text { Phase 2 safety and acceptability } \\
\text { study, comparing daily and } \\
\text { coitally dependent use }\end{array}$ & Gilead/NIAID \\
&
\end{tabular}

Population Council/USAID/

Bill \& Melinda Gates

Foundation

Cape Town, Durban, and

Population Council/US CDC-

Pretoria, South Africa

Thai Ministry of Health

Collaboration/Bill \& Melinda

Gates Foundation

CONRAD/Polydex/Family Health Benin; Burkina Faso;

International (FHI)/USAID India; South Africa; Uganda

Indevus/NIAID Pune, India

Indevus/Microbicides Develop- Durban, Johannesburg, and

ment Project (UK Medical Mtubatuba, South Africa

Research Council and DFID)

Mwanza, Tanzania

Masaka, Uganda

Mazabuka, Zimbabwe

Accra and Kumasi, Ghana

lbadan and Lagos, Nigeria

Pune, India

Birmingham, Alabama, and New

York City, New York, United States

\section{PILL FOR PRE- (HIV) EXPOSURE PROPHYLAXIS (PREP)}

Tenofovir

Phase 2 safety and effectiveness

trial in high-risk men and women

Gilead/Family Health Inter-

national/Bill \& Melinda Gates

Douala, Cameroon

Foundation

Tenofovir

Phase 2/3 trial assessing safety and efficacy of daily prophylaxis

Gilead/CDC in reducing HIV transmission among young adults
Tema, Ghana

Ibadan, Nigeria

Francistown and Gaborone,

Botswana

\section{PILL FOR TREATMENT OF HERPES SIMPLEX-2 VIRUS}

Acyclovir

Phase 3 trial of acyclovir for HSV-2 suppression among HIVdiscordant couples
University of Washington/Bill
\& Melinda Gates Foundation

Gaborone, Botswana

Nairobi, Kisumu, and Eldoret, Kenya

Kigali, Rwanda

Cape Town and Johannesburg,

South Africa

Moshi, Tanzania

Kampala, Uganda

Lusaka and Ndola/Kitwe, Zambia

HIV VACCINE

Bivalent B/E rgp

20 HIV vaccine

Phase 3 efficacy trial among injecting drug users

VaxGen/Thai Ministry of Public

Health and US CDC

Note: Adapted from Friedland (2005).

a Unless indicated otherwise, the objective of the trial is reduction in HIV transmission.

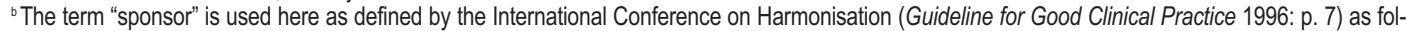

lows: "An individual, company, institution, or organization which takes responsibility for the initiation, management, and/or financing of a clinical trial." 


\section{Setting the Stage}

\section{Informed consent is a central tenet of research ethics reflected in documents and guidelines dating back to the Nuremberg Code (NCPHSBBR 1949), through the} Declaration of Helsinki (1964) and its revisions, the Belmont Report (1979), the Council of Europe (1997), and the Nuffield Council on Bioethics Guidelines (2002). Although definitions vary and the specifics of implementation have evolved somewhat over time, informed consent is based on three main premises: disclosure—providing information, appreciation-participant's understanding, and voluntariness - the ability to enroll in a trial and to leave it voluntarily (Singh 2005).

\section{Basic Ethical Principles in the Belmont Report}

Respect for Persons: Individuals should be treated as autonomous agents, and persons with diminished autonomy are entitled to protection.

Beneficence: Possible benefits of research should be maximized and possible harms minimized.

Justice: Those who realize the benefits of research should share in its burdens, and those who share in its burdens should also realize the benefits.

A number of national and international bodies provide regulations and guidance on the conduct of informed consent, including the International Committee on Harmonisa- tion (ICH), the US Food and Drug Administration (FDA), and the US Office of Human Research Protections (OHRP). These regulations lay out the broad areas that must be addressed in informed consent documents (for example, see box on page 6: Basic Elements of Informed Consent). These guidelines, in varying specific terms, indicate that the principal investigator is responsible for providing information in a manner that is understandable to the research participant and that the prospective participant should be given sufficient time to consider whether to participate or not. All guidelines and regulations include requirements for documentation of the consent process, whether or not the study participant can read and/or write.

However, these regulations offer little guidance on specific approaches to use to ensure informed consent-how information should be presented or what tools should be used for doing so. ICH guidelines suggest that the principal investigator is responsible for ensuring that "information in the consent form and any other written information was accurately explained to and apparently understood by the subject ..." (ICH 1996: 16), but they offer no specific guidance or standards for assessing this "explanation" or "understanding." Similarly, the United States Code of Federal Regulations, which applies to studies conducted under the auspices of the US FDA, states that "the information that is given to the subject or the representative shall be in a language understandable to the subject," but includes nothing about researchers' responsibilities for ensuring study participants' comprehension (OFR 2002). 
Basic Elements of Informed ConsentUS Code of Federal Regulations: 45

\section{CFR 46.16}

In seeking informed consent, the following information shall be provided to each subject:

1. A statement that the study involves research, an explanation of the purposes of the research and the expected duration of the subject's participation, a description of the procedures to be followed, and identification of any procedures which are experimental;

2. A description of any reasonably foreseeable risks or discomforts to the subject;

3. A description of any benefits to the subject or to others which may reasonably be expected from the research;

4. A disclosure of appropriate alternative procedures or courses of treatment, if any, that might be advantageous to the subject;

5. A statement describing the extent, if any, to which confidentiality of records identifying the subject will be maintained;

6. For research involving more than minimal risk, an explanation as to whether any compensation and an explanation as to whether any medical treatments are available if injury occurs and, if so, what they consist of, or where further information may be obtained;

7. An explanation of whom to contact for answers to pertinent questions about the research and research subjects' rights, and whom to contact in the event of a researchrelated injury to the subject; and

8. A statement that participation is voluntary, refusal to participate will involve no penalty or loss of benefits to which the subject is otherwise entitled, and that the subject may discontinue participation at any time without penalty or loss of benefits to which the subject is otherwise entitled.

Source: Office of the Federal Register (2002).
Existing literature and the experience of meeting participants suggest that clinical trial participants often have difficulty understanding the information presented in informed consent materials. When informed consent forms present comprehensive information about a trial-either to provide the trial volunteer with all relevant information or to provide legal protection for the trial—-trying to understand them can be overwhelming for the trial volunteer. These forms-sometimes more than ten pages of dense, single-spaced text-are visually complex and often include highly technical language. Translation can make technical terms and concepts even more difficult to understand. These challenges are exacerbated in settings of low literacy, where potential research participants may have little understanding of disease processes or research, and where local languages may lack terms for key research concepts.

In practice, some of the regulations designed to protect research participants may undermine the informed consent process, albeit unintentionally. For example, in some settings, any signed paper is perceived as a formal contract- "like signing a bank check" - so a signature on an informed consent form may connote a binding obligation (Pennington 2005). Participants may feel unable to break such an agreement even if they wish to withdraw from the trial and have been told that they have the right to do so. In such a setting, requiring a trial participant to sign an informed consent form may contradict the concept of voluntarism and the right to withdraw. It may also create a barrier to participation if concerns about the meaning of a signature outweigh the desire to participate. 
In the absence of consistent regulations and guidance, informed consent documents and processes can be influenced heavily by ethics committees or institutional review boards (IRBs). IRBs play a critical role in providing ethical oversight and protecting research participants. In practice, however, the current IRB system can vary considerably among different institutions and, in certain settings, can operate with little standardization, transparency, or accountability. An IRB's capacity to review appropriately a diverse range of clinical and related behavioral research can be strained in any institutional setting. These limitations can be of particular concern in the context of large international and multisite trials when IRB members may have little or no familiarity with the trial setting.

Collaborative trials with multiple IRB reviews often face reconciling sometimes competing and contradictory requirements and recommendations regarding informed consent approaches, forms, and supplementary materials. For example, a situation arose in which a US-based IRB required that a study's informed consent form contain language describing possible DNA testing and disclosure of paternity status. Because no DNA testing was being performed at one of the non-US collaborating study sites, its IRB felt the language regarding DNA testing should be deleted from the form. The USbased IRB, however, insisted that its legal department required that this language be included on all consent forms for studies and sites for which they have oversight (Pennington 2005). Workshop participants noted that the ethical safeguards provided by IRBs, although critical, in practice can hinder the development and implementation of informed consent processes that are appropriate and responsive to a range of trial participants and settings. 


\section{Factors Influencing Informed Consent}

Informed consent is premised on the notion that individuals have the right and the ability to make decisions in their own interest and to act upon them.

In reality, the ability to make decisions, as well as the decisions themselves, are often constrained by a range of factors. For example, in many settings, important decisions are not made by individuals. A decision may be influenced or made by a family member, family group, employer, or the community, more broadly, which is particularly true for many women in settings where decisions are traditionally made by men. Women may not have the autonomy or the legal right to make the kinds of decisions encompassed by informed consent. Issues of autonomy and decisionmaking can be especially complex for HIV prevention trials that are enrolling healthy people, and can raise highly charged issues concerning sex, trust, gender and power. Finally, it is important to recognize that decisionmaking is characterized by the complexity and contradictions inherent in human nature and human behavior.

The workshop highlighted broad contextual considerations as well as specific issues that influence decisionmaking regarding consent to participate in a clinical trial: risk perception; remuneration; community influence; and the use of informed consent advocates.

\section{Informed Consent in Context}

HIV prevention trials take place within a complex and layered series of contexts: the trial itself, the social setting of the local community where the trial takes place, and the broader legal, political, and economic arena that has global as well as local dimensions. Factors external to the trial and the local community can affect perceptions of a trial and individual decisions about trial participation. For example, a study of willingness to participate in an HIV vaccine trial documented a significant decline in willingness at one of the trial sites. This decline followed a misleading headline in a local newspaper indicating that the vaccine had "failed" to prove protective in a Phase 2 trial (a trial that was not, in fact, measuring effectiveness) (Bartholow et al. 1997). Trial participants exist within a complex web of relationships that may have a strong influence on their perceptions and actions related to issues of trial "ethics." In HIV prevention research, this situation can be exacerbated by stigma, judgment, and fear. Participants' perceptions or experience with authority may make them feel unable to leave a trial even if they are assured repeatedly that they have a right to do so. Evaluation of an informed consent process among women attending an antenatal clinic who were recruited for a perinatal HIV-transmission study showed that although they responded "yes" when asked if they understood that they were free to leave the study at any time, almost none of the participants believed that the hospital would allow them to quit the study. One-fourth to one-third of the respondents thought that their care would be compromised if they left the study (Abdool Karim 1998).

Although a particular trial may work to support and respect the dignity and rights of participants, most populations at risk of HIV 
are marginalized and vulnerable because of factors such as gender, sexual orientation, poverty, education, use of injecting drugs, or sex work. Clearly, trials must not exploit or intensify this vulnerability, yet neither can they redress the broader social, economic, political, and legal factors that condition it. It can be difficult to anticipate participant and community perceptions of many trial ethical obligations and decisions. For example, benefits offered as part of a researcher's ethical obligation or to enhance participants' benefits, such as antiretrovirals or other medical care, may be perceived as unfairly and inappropriately creating an inequity within a family.

\section{Risk Perception and Decisionmaking}

Weighing potential risks and benefits is crucial to fully informed consent, and the field of risk perception offers a number of insights for prevention research. In communication campaigns as well as research settings, "risk" tends to be presented in terms of quantitative estimates that emphasize the probabilities of particular outcomes. Research on risk perception suggests that people of all educational backgrounds generally find applying such quantitative estimates to actual decisions and actions difficult (Downs 2005). Therefore, when risks must be "quantified," people may better comprehend broader concepts that allow comparison among "high" and "low" risk, rather than comparison among specific percentages or numeric estimates. Generally, a more qualitative presentation and understanding of risk is likely to be more relevant to people's decisionmaking. The presentation should capture both dimensions of risk: its magnitude and the likelihood of its occurrence.

Myriad background factors, including ethnicity, socioeconomic status, and sense of agency, can also influence how individuals assess risk and the actions they take as a result. An essential corollary to risk assessment is whether individuals or communities trust the source of information to represent the risk accurately. This trust is influenced by whether an individual or group has had a history of positive or negative experiences with the health system, with law enforcement, with research institutions, or with government. In the generally resource-poor settings where HIV prevention trials are being conducted, it is critically important to recognize the historical backdrop of colonialism and racism, and ongoing challenges of poverty and exploitation. In this light, building and maintaining trust among researchers, communities, and participants can be a critical element of informed consent.

\section{Impact of Participant Remuneration on Informed Consent}

Compensation is widely recognized as a critically important factor influencing voluntariness of trial participation. However, regulations and guidelines for informed consent are vague about where the distinctions can reasonably be drawn between "fair compensation" and "undue inducement." This vagueness is particularly problematic in resource-depleted settings and in multicenter trials. In reality, an "inducement" of some kind is inherent in every research endeavor, and most trials provide participants with money, health care, or other benefits.*

\footnotetext{
* The complexity of this issue is exemplified by the way in which language is used. Although many associated terms (such as "compensation," "remuneration," "reimbursement," and "benefit") have specific technical definitions, they can be used imprecisely and interchangeably. Capturing the precise meaning of these terms is further complicated by translation in many trials.
} 
Three general models have been proposed for determining appropriate payment for research participants (Dickert and Grady 1999). The "market model" suggests payment according to "market forces" such as the levels of risk and benefit, scarcity of potential participants, and the arduousness of the protocol. This model is generally rejected as unacceptable because high payment could too easily overshadow an appropriate assessment of risks. In the "reimbursement model," participants receive payment for expenses and, in some cases, for missed wages that are directly related to study participation, without taking into consideration effort or discomfort. A key drawback of this model is that each participant will receive a different amount of money. The "wage-payment model" equates research participation with unskilled labor and standardizes the "wage" associated with trial participation. A potential problem with this model is the commercialization of trial participation, which might also warrant the inclusion of typical employment benefits, such as insurance and comprehensive health care. Although these models are useful, each has shortcomings in implementation. Determining which model might be the most appropriate in a particular setting is essential. Further research is needed in order to better understand the impact of remuneration on informed consent and voluntary participation.

Controversy around the issue of balancing compensation with inducement was played out recently in South Africa when the Medicines Control Council (MCC) mandated a reimbursement of 150 Rand (US\$25) per visit for all clinical trials. This amount reflected the MCC's desire to make remuneration fair and equitable for study participants across trials, settings, and economic status. Some research ethics committees, however, questioned whether this payment represented excessive remuneration, becoming an "undue inducement" for people from the poor, often vulnerable communities where HIV/AIDS research generally is conducted (Moodley 2005).

Several recommendations were offered for addressing this ongoing controversy: empower ethics committees to guide remuneration decisions; determine remuneration on a case-by-case basis with, perhaps, a common minimum amount; examine the effect of the timing of disclosure of remuneration on the decision to enroll in a trial; and base decisions about remuneration on empirical research among ethics committees, investigators, and participants. A suggestion was made at the workshop that in addition to providing benefits to individuals who participate in the trials, research communities might also be provided with benefits such as post-trial access to products that are proved effective.*

\section{Defining the Trial "Participant(s)"} HIV prevention trials can pose a number of challenges regarding autonomy and disclosure for trial participants, particularly trials that enroll women. For example, in many settings, microbicide and diaphragm trials that enroll women grapple with how and how much to involve men in decisionmaking and in the trial itself. Other trials, such as certain microbicidesafety studies and an efficacy trial of acyclovir

\footnotetext{
* The "fair benefits" model explores this and other types of benefits that could be negotiated among researchers, sponsors, and host-country stakeholders. For more information, see Participants in the 2001 Conference on Ethical Aspects of Research in Developing Countries (2002).
} 
for suppression of herpes simplex virus (HSV2), are enrolling couples. Presentations and discussions at the workshop highlighted a number of models for addressing sexual partnership issues in prevention trials:

- community outreach and provision of information to men to ensure community support for the study;

- counseling and informing trial participants' husbands or partners only at the participant's request;

- requiring formal consent from partners for women to enroll in a study;

- considering sexual partners as "participants" whose consent is required if they are likely to be exposed to the experimental product (such as a microbicide); and

- enrolling both partners as trial participants in couples studies.

Questions about the appropriate role for men in studies that enroll women touch on issues of autonomy, transparency, confidentiality, and local cultural norms that govern gender relations. As a practical matter, involving men, up to and including requiring formal partner consent, may be seen as necessary for respecting cultural norms, ensuring community support and transparency, and allaying suspicion and rumor. Paradoxically, in studies testing female-initiated methods like microbicides and diaphragms that are designed to give women more autonomy and control, requiring partner consent will compromise the trial participant's autonomy and confidentiality, critical elements of research ethics.

In large-scale studies enrolling diverse populations, obtaining consent from partners may not be feasible. For example, trial partici- pants may have complex partnership arrangements that they do not wish to acknowledge, including multiple partners, extramarital partners, casual partners, or commercial sex partners. Although there was no clear consensus on how to address this issue, workshop participants acknowledged that the best approach should respond to practical considerations while not compromising women's autonomy. One strategy being used by a number of studies to balance these competing concerns is to provide general information to the community and to support women who wish to inform or involve their partners, relying on the woman's suggestion and discretion. A variety of approaches can be used, such as development of informative materials, male partner information sessions, or couples counseling.

Researchers seeking to enroll couples into trials also face difficult issues related to informed consent, as illustrated by two examples presented at the workshop. The first is a Phase 3 randomized controlled trial of acyclovir for suppression of HSV-2 to prevent HIV transmission among HIV-discordant couples, being conducted by the University of Washington's Partners in Prevention. The hypothesis is that suppression of HSV-2 in HIV-positive partners using acyclovir twice a day for a year will reduce transmission to the HIV-negative partner by half. (Mujugira 2005). More than 3,600 couples will be enrolled at sites in six African countries and in India.

The recruitment strategy is based on couples' voluntary counseling and testing (VCT). Research staff have invested considerable resources in retraining VCT counselors to work with couples rather than with individuals. To address people's concerns about testing positive and informing a partner, couples are encour- 
aged to be tested and find out their HIV status together. Because both partners must understand the overall concept of the study, it is explained to them jointly. However, some of the study procedures differ for the HIV-positive partner and the HIV-negative partner, so the consent process and forms also differ. A more serious concern is the potential for coercion, exacerbated by the gender power imbalances that generally leave the man as the final decisionmaker. To address concerns around providing clear information and ensuring that women are not coerced to join the study, the consent is administered separately to the partners.

A second study involved $55 \mathrm{HIV}$-negative, low-risk couples in a Phase 1 safety study of the candidate microbicide Carraguard ${ }^{\circledR}$ (Chaikummao 2005). Researchers in Chiang Rai, Thailand, found it challenging to engage men, because they were less concerned about their own risk behavior or health-related issues than were their wives or partners. Many men faced constraints in coming to the clinic because of work commitments. The study team found that only couples with good relationships were likely to enroll and that even so, participants were concerned about disclosing their test results to their partners. Participation in the couples study also had benefits, including improved communication between partners about sexual pleasure, risk, and HIV prevention.

\section{The Informed Consent Advocate}

In its microbicide and pre-exposure prophylactic (PREP) trials, FHI has been experimenting with employing an "advocate" to help ensure informed consent (Attafuah 2005). This innovative effort provides additional support to ensure that trial volunteers, especially those who may be illiterate, understand the study at the time of consent. An independent witness, employed under a contract separate from that of the trial, observes the consent process to verify that the consent form is reviewed in full, that the potential participant's questions have been addressed satisfactorily, and to look for any indication that the participant may not fully comprehend the information provided prior to signing the consent form. If the advocate perceives a problem with regard to comprehension, and the problem cannot be satisfactorily resolved, the advocate has the authority to determine that the person is ineligible to participate in the trial, just as research staff conducting the informed consent process would be able to do.

A number of workshop participants raised concerns about whether such a mechanism — which may be perceived as delegating decisionmaking to a third party-compromises the trial volunteer's autonomy. Further discussion indicated that use of the term "advocate" may imply a more active role than was the case in this instance and that "witness" might be a better description.

In general, workshop participants felt that the strategy represented an innovative effort to preserve participant confidentiality while responding to the regulatory requirement to provide an independent witness for illiterate participants. Given the complexity of issues and participants' needs that are likely to emerge in large-scale HIV prevention trials, and the lack of experience to draw on, it is important for staff, communities, and researchers to feel empowered to experiment with new and creative approaches to respond to participants' needs. 


\section{Community Involvement and Informed Consent}

The extent to which community engagement infuses the informed consent process was striking throughout many workshop presentations and discussions;

working with communities is an integral part of the informed consent process in many HIV prevention trials. Communities play a variety of roles in the informed consent process: they formulate approaches to information provision; help to develop, review, and test materials; and alert researchers to emerging community concerns. Many of the trials represented at the workshop consider community outreach and involvement to be an important first step in informed consent. In most settings, community outreach and involvement was linked to the informed consent process whether formally or informally.

The HIV Prevention Trials Network (HPTN) 035 trial provided a useful case study of approaches to developing an informed consent process that can be implemented consistently across multiple sites in diverse cultural settings. HPTN 035 is a fourarm randomized Phase 2/2b trial of two candidate microbicides and two control arms that will enroll 3,220 women in five countries. The HPTN informed consent process is built on a conceptual model that recognizes the links between the community and the individual and the interrelationships among the community's introduction to the study, the administration of informed consent to the individual, and the community's and individ- ual's evolving perceptions of the study (Woodsong and Karim 2005). This model acknowledges that the community's perceptions and experiences will influence individual decisions about trial participation and that individuals' experience, in turn, will help shape community perceptions and support for others to enroll in the study. Informed consent is embedded in an overall process of community consultation and involvement aimed at preparing the community for research and the research for the community. Similar approaches are being taken by a number of other trials represented at the workshop.

An ongoing challenge in community participation is defining the "community." In relation to research participation, it can be defined as the group of people likely to be affected by, or have an influence on, the decision of participants to join the research. Family, friends, and peers; local administration; and local groups such as churches, clubs, and youth and advocacy groups can have varying degrees of influence. Most workshop participants recommended defining the community broadly to engage a wide array of stakeholders: potential trial volunteers, community leaders and activists, members of the ethical review committee, and national and even international civil society. Such a broad definition of community poses challenges, however, including how to preserve participants' confidentiality as well as how much information should be presented to which constituencies at which point in the process. 
Another approach to defining community is to ask people who are likely to be recruited for a trial to describe what communities or other important social groups they belong to or identify with and who they feel can best represent their interests. Social science research methods can be used to describe the diversity and cohesiveness of these participant stakeholder communities. This information can help guide decisionmaking about how to build effective partnerships with communities and ensure that spokespersons can represent fairly community and research participants' concerns (Weijer and Emanuel 2000;

MacQueen et al. 2001).

Some studies use a detailed recruitment session that also serves as a way to inform community members about the trial. A number of workshop participants argued that all information about the study should be introduced and explained during outreach visits. Others maintained that this approach was too burdensome for the participants and the research staff and that more general information should be provided together with contact information so that people who are interested and want additional information can follow up.

A related concern is balancing the need and desire for transparency with the necessity of maintaining confidentiality and the possibility of stigmatizing potential trial participants. In HIV prevention trials, where testing positive is an exclusionary factor, potential trial participants who screen out of a trial may be assumed to be HIV-positive. In some set- tings, anything related to HIV, including a prevention trial, could stigmatize participants.

Based on rich experience, there is an ongoing and evolving debate about — and experimentation with-how community involvement in clinical trials can best be facilitated. The most common approach has been to establish structures such as a committee or board specifically for soliciting input or advice from the community. Often referred to as community advisory boards (CABs), ${ }^{*}$ they have played a pivotal constructive role in many settings by fostering dialogue, developing common understanding, reviewing protocols and research approaches, and building trust. It is important to cultivate and train a cadre of people to answer questions accurately and openly on topics about which people may be reluctant to ask study staff directly. Community advisory boards can help to reinforce key concepts such as voluntarism and aid in the appropriate assessment of risks and benefits. With regard to informed consent, the community advisory board and other community structures can assist with developing language, terms, and analogies to convey research concepts.

Some participants noted that CABs also have limitations. They may not represent community views or interests, and they can become entrenched or "colonized" by the trial. It can be especially difficult for marginalized groups such as injecting drug users and sex workers or, in some settings, women and young people, to be heard and represented through such formal structures. CABs may also need training in research methods and

\footnotetext{
* Studies represented at the workshop referred to these structures as community advisory boards (CABs) or community advisory groups (CAGs). The two terms are used interchangeably in this report.
} 
ethics to help members better understand research concepts and ensure that they will respect the confidentiality of those who seek their advice (Rivera et al. 2004). Multiple strategies are needed to hear diverse voices, and new approaches are being explored that could supplement CABs (Hantman and Gottemoeller 2004).

Several workshop participants cautioned that it is critically important to define the roles that researchers and community members will play in any partnership. Articulating advisory, information-giving, and decisionmaking roles clearly is especially important in light of growing demands for communities' involvement in setting priorities, developing protocols, and designing research—not just in implementing trials. Given the increasing emphasis placed on community consultation, one participant questioned why more community members were not at the workshop. Organizers noted that a researcher-community dialogue about informed consent was beyond the scope of this meeting, but recommended such a dialogue as a follow-up action. Much of what was presented at the workshop had, in fact, grown out of dialogue among researchers and community members at trial sites.

A broad definition of "community" has also been adopted for the Botswana Oral Tenofovir Prophylaxis Trial, a study to evaluate the safety and efficacy of daily oral tenofovir pre-exposure prophylaxis in reducing heterosexual HIV transmission among young women and men aged 18-29 (Chillag 2005). This randomized, double-blind, placebocontrolled trial is being conducted by the BOTUSA Project - a collaboration of the Botswana Ministry of Health and the US
Centers for Disease Control and Prevention. Prior formative research underscored the importance of informing participants, partners, and the community through a consultative process that, in turn, informs the researchers. The trial team sought the opinions of a diverse range of partners among researchers, participants, and the community using a variety of mechanisms including advisory groups, community meetings, and individual interviews. In addition to community advisory groups in each site, the trial uses participant advisory groups and consults regularly with a range of other community stakeholders. The study employs two full-time community liaison officers who are well trained and connected in the community and who work closely with local and national ethics committees. Formal rapid assessments conducted every six months provide an opportunity to monitor what is being said in the community. These assessments also help address questions and concerns, clarify issues, and dispel myths and rumors that emerge.

A presentation from the HPTN 035 study site in Zimbabwe highlighted many of the issues related to community involvement in informed consent, and in trials more broadly, that came up throughout the meeting (Chigwanda 2005). Community involvement in decisionmaking is embedded in the cultural tradition of Zimbabwe, in which the participant is a member of a variety of social groups and responsive to a range of social influences. A significant number of people rely on natural support systems such as families, friends, clubs, church, or other organizations - rather than on professional or formal groups - when weighing a decision about 
participating in a trial. In this setting, mobilizing the community included consulting with relevant structures in the community, recruiting advisors and opinion leaders, and raising awareness through informational meetings and materials. The trial site has a
$\mathrm{CAB}$ that has played an important advisory role in developing and testing key messages and materials for informed consent. Implicit in these strategies is consulting widely and listening to community concerns, ideas, and priorities, as well as providing information. 


\section{Tools to Enhance the Informed Consent Process}

Recognizing the limitations of standard informed consent forms, investigators and trial staff are experimenting with a range of additional tools and processes to enhance informed consent.

Workshop participants shared and discussed a number of thoughtful and innovative strategies, materials, and ideas for conveying difficult concepts. Tools that are being developed and used include study booklets, pamphlets, fact sheets, radio and newspaper advertisements, videos, audio computer-assisted selfinstruction (ACASI)*, and flip charts. Some trials also use other visual aids, such as blood vials, speculae, product boxes, and randomization envelopes, to illustrate particular trial procedures. Many of the trials use these materials in combinations that build on and reinforce each other to present relevant information to the community, volunteers, and participants throughout the process of a trial by means of community outreach, information sessions, recruitment, screening, enrollment, and follow-up visits.

These materials and approaches have been developed through careful formative research, drafting, pretesting, and adaptation, and are being employed in clinical trials in a variety of settings. Workshop participants underscored the complexity of developing such materials and the importance of engaging professionals with expertise in developing communication and education materials, because few clinical trial teams include such experts. Developing these materials also requires an extensive understanding of the trial protocol and of the setting. In most settings, study staff, community advisory board members, participants from earlier trial phases, and potential participants are engaged in generating ideas, developing approaches, and pretesting and reviewing materials.

Multicenter trials generally require translation into multiple languages and design modifications to ensure that the visual depiction of people, settings, and concepts resonates with diverse communities and participants. The meaning of certain drawings or color choices may differ among settings. Some trials have developed an overall template for design and information that is completed with details tailored to each setting. Incorporating protocol changes and responding to questions or unanticipated issues that emerge in the course of the trial can pose particular challenges, especially when producing materials such as booklets or videos that require a long lead time to create and that must be printed or reproduced. Some trial teams have addressed this problem by creating more flexible fact sheets or frequently asked questions (FAQs) to target specific groups (such as male partners of women in microbicide trials) or topics (such as HIV testing), because they are less complicated to

\footnotetext{
* In this context, ACASI is used to refer to audio computer-assisted self- "instruction" rather than self"interview," as it is more commonly known. In the BOTUSA Project trial site, the technology is used to provide information to volunteers and participants rather than as an interview technique for eliciting responses on sensitive topics.
} 
produce and can be adapted relatively easily and inexpensively.

Workshop participants acknowledged that developing and using informed consent tools for HIV prevention trials is still a relatively new area. Little evidence exists concerning whether and how the time and effort invested in developing and employing these materials enhances participants' understanding of trial concepts or their adherence to study procedures. This section of the workshop report explores a range of issues related to developing, adapting, and using materials designed to enhance the informed consent process: formative research; developing and using specific tools; targeting trial information and tools for specific audiences; explaining difficult concepts; and training staff.

\section{Formative Research}

Formative research is critical for identifying and developing clinical trial sites and for informing specific approaches to protocol design and implementation. Often it is conducted concurrently with site-preparedness activities and can also present opportunities to establish initial contact with community leaders and members. Formative research can be used to assess general questions critical to the trial, such as a community's perceptions and openness to the research, potential participants' background knowledge of HIV/AIDS and related health and social issues, and approaches to structuring community participation. It can also inform practical decisions related to trial implementation, such as where to locate clinics and recruitment sites to maximize participants' convenience and to protect their privacy. Finally, this initial research is also crucial for determining a community's knowledge of and preconceptions about health and the research process, concepts that may be difficult to explain. It may also suggest creative and accessible ways to explain these concepts.

HIV prevention trials have used a variety of approaches to formative research with varying degrees of formality from community meetings to interviews or focus-group discussions with key informants, community leaders, potential trial participants, other community members, and the health professionals who serve them. A number of key issues have emerged from this process.

The BOTUSA Project's PREP trial, for example, included an extensive process of formative research and community preparedness that led the project team to be concerned about therapeutic misconception (that people would mistakenly think that the test products and/or placebo were known to be effective) and about behavioral disinhibition (participants' neglect of risk-reduction practices based on their belief that the test product and/or placebo is effective). The findings also underscored the importance of transparency (including educating the community, participants, and partners) and of communities' high levels of hope for new HIV prevention interventions in the face of the epidemic. These findings influenced the design of the trial's community consultation process (see section above on community involvement and informed consent). As a result of the findings, all educational and informed consent documents and processes explicitly reinforce the experimental nature of the trial. At the time of the workshop, participant enrollment had not yet begun, so the effectiveness of these measures is not yet known. 
To inform approaches for the Phase 3 efficacy trial of Carraguard being implemented at three sites in South Africa, the Population Council conducted focus-group discussions and in-depth interviews with trial participants and study staff at two of the study sites that had been involved in an earlier Phase 2 safety study (De Kock et al. 2005). This research assessed comprehension of the trial's purpose and procedures, identified ways to explain difficult concepts, and solicited recommendations for recruitment and informed consent processes for the Phase 3 trial. Phase 2 participants recommended strongly that the study team develop a video to present basic trial information and explain difficult concepts; they felt that a video would be more engaging and informative than print material or presentations by study staff, especially for recruitment.

Based on this formative research, the Population Council developed a video to explain difficult or unfamiliar concepts, including randomization, use of a placebo (now referred to as the "comparison gel"), and voluntary participation. To underscore that participation in the trial is voluntary, the video uses vignettes featuring a participant from the Phase 2 study, as well as a volunteer who enrolled and later chose to withdraw from the trial. The video also depicts a pelvic exam, a procedure that was unfamiliar to most women in the trial communities.

Workshop participants noted that because formative research often is conceptualized and perceived as primarily intended to inform clinical trial processes, the data are rarely analyzed, presented, or disseminated as discrete research, and the richness of the research design and findings can be lost.
Designing informed consent and other processes for HIV prevention trials—such as strategies for recruitment and retention of participants, locating facilities, or developing a community partnership—presents enormous challenges. The field is growing and evolving rapidly, and many trials are being planned in similar sites and communities. Therefore, making the findings of formative research more readily available across studies could contribute significantly to improving trial processes and to targeting and streamlining future formative research. For example, when HPTN research staff learned from Population Council staff about participants' concerns regarding the pelvic exam, they incorporated an illustration of a pelvic exam into the HPTN consent materials. Workshop participants strongly recommended that researchers consider findings from formative research as important in and of themselves, and, whenever possible, allocate resources for publishing, sharing, and disseminating formative research findings across trials.

\section{Informed Consent Tools}

As described above, all of the HIV prevention trials represented at the workshop used a variety of additional educational tools and materials to enhance study volunteers' understanding of trial concepts and procedures. Some of the challenges and successes experienced in developing and using these supplemental materials are explored below.

\section{Booklets}

Illustrated booklets are used to provide information for many of the studies represented at the workshop. Some were designed to provide general information about the research, 
whereas others are more comprehensive. For example, the informed consent form for the Carraguard Phase 3 microbicide trial provides basic required information (see box on page 23: Carraguard Trial Outreach) according to regulatory guidelines, and the booklet supplements the form, giving more details and comprehensive information about previous testing of Carraguard and the placebo. Workshop participants engaged in a lively discussion about the usefulness of booklets and how they could be, and actually are, used. In response to a question about whether the women in the trials actually used the booklets on their own, several study staff members noted that participants in the trials rarely seemed to refer to the booklet for information and preferred to have their questions answered by a counselor. To underscore to participants that the booklet contains answers to many of their questions and can be used as an ongoing reference, some trials ask counselors to refer to the information provided in the booklet when responding to questions during one-on-one or group sessions. Some staff suggested that booklets help with recruitment because women who are considering enrolling or who already are enrolled in the trial show them to friends or relatives who may be interested in participating.

During pretesting, potential participants voiced specific opinions about the images, color, and production quality of booklets. Potential study volunteers felt that a wellprinted color booklet conveys a trial's professionalism and its respect for participants. Several experts at the workshop suggested that using color can help participants understand and retain information because color images look more lifelike than black-andwhite ones. Documenting the efficacy of color in trial settings would be useful for providing evidence that more expensive production is cost-effective.

The booklet used in the HPTN 035 microbicide trial uses line drawings and a character, "Serena," to explain many of the study's concepts and procedures. This multisite trial is being conducted at eight sites in six countries, and the materials, including the illustration of Serena, were adapted to suit each setting (see box on page 21). All HPTN trial materials have undergone a two-stage pilot test, incorporating a number of revisions at both stages.

Serena was modified according to the results of the pretests to elicit respect and confidence. Although study staff intentionally designed Serena to look familiar to the women being

\section{Evolution of "Serena" for HPTN 035}
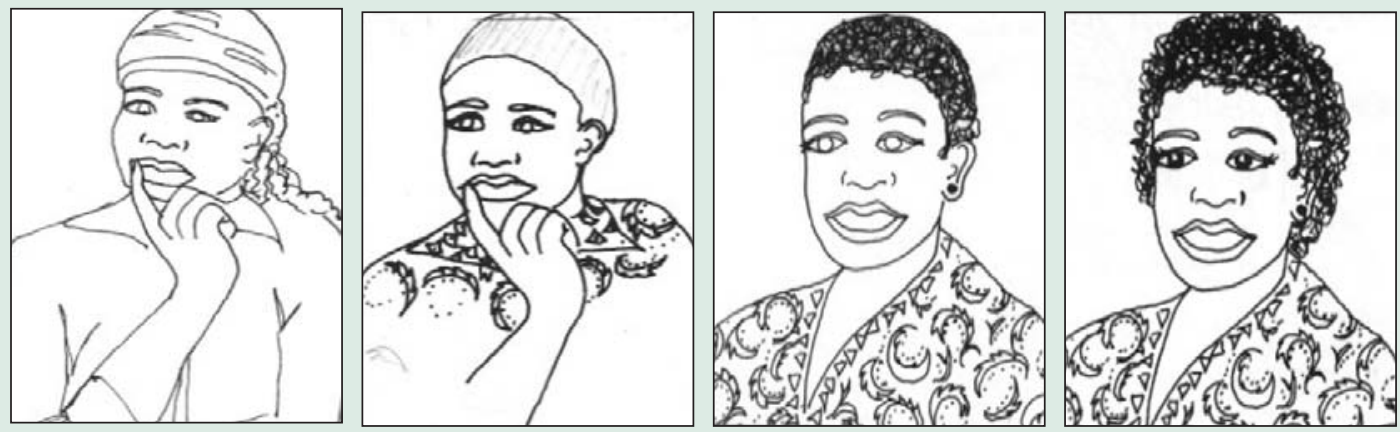

In pretests, participants helped to develop Serena, used in the booklets for the trial. (Artwork by Denise Todloski) 


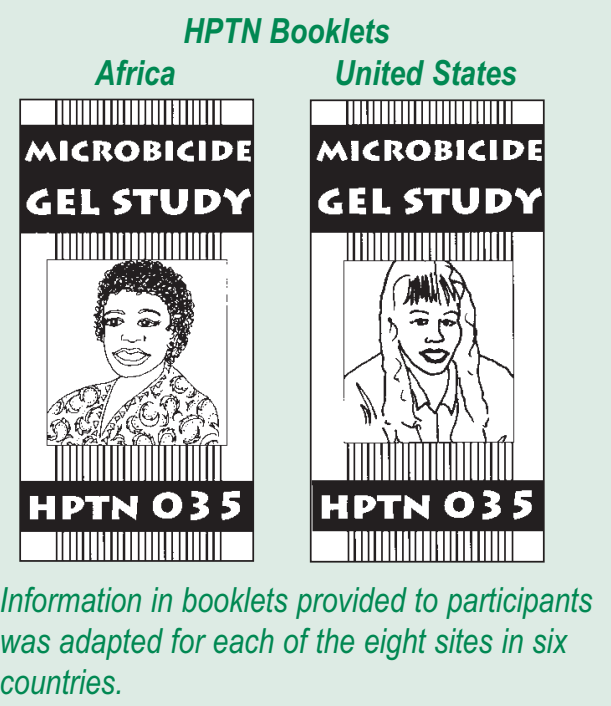

recruited for the trial, pretesting indicated the women's strong preference for her to be a more "aspirational" figure. Therefore, Serena was redrawn to appear modern, attractive, and affluent. One drawing in the booklet was designed to make Serena appear reflective and thoughtful as she considered whether to join the study (see box on previous page). Instead, potential participants thought the picture of Serena with her forefinger on her lips made her look worried, which could raise concern among volunteers considering enrollment. Similarly, participants in the Phase 2 Carraguard trial recommended that the illustrations be more realistic than the cartoon style of the Phase 2 booklet. The Carraguard Phase 3 booklet has a more professional look, with more realistic illustrations, higher-quality paper, and a glossier texture (see box below).

\section{Video}

Three trials represented at the meeting are using videos to provide information for recruitment and informed consent: the MIRA (Methods for Improving Reproductive
Health in Africa) trial of the latex diaphragm to prevent HIV acquisition among women, the HIV/HSV Partners in Prevention trial, and the Carraguard Phase 3 microbicide trial. All three are using video for its potential to ensure consistency in how information is presented and to reduce the burden on staff by providing essential basic information about the trial. Video is also perceived as a more engaging approach than print media, especially for people with low literacy. Staff in the MIRA trial found that people at recruitment sessions and participants tend to become bored by written materials or by hearing staff present trial information and indicated that a video would help keep them interested. This suggestion echoes participants' recommendations from the Carraguard Phase 2 trial.

The Carraguard Phase 3 video uses vignettes to convey key aspects of the study that participants in the Phase 2 trial found challenging: voluntary participation, communication with a partner, the pelvic exam, and HIV test-

\section{Carraguard Booklets}

Phase 3
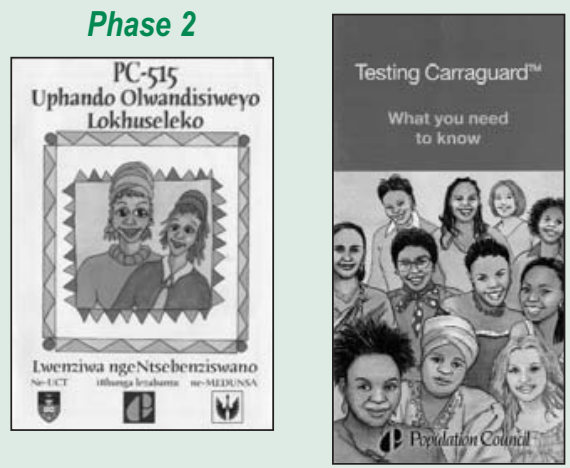

Study participants in the Phase 2 Carraguard trial recommended that illustrations for the information booklet (left) be more realistic. Changes were made to the Carraguard Phase 3 booklet (right). 
ing. Other difficult concepts, including randomization and use of a placebo are explained using animation. An educational consultant worked with the trial team and the video production company to develop the script, and a well-known and trusted actress is the on-camera narrator in the video. Initial sections were pretested and adapted following focus-group discussions with community members and the community advisory groups at two of the trial sites.

Clinicians, community members, and the research team were also involved in developing the video for the MIRA trial. The chair of the ethics committee agreed to appear in the video, helping to give a real face to the concept of the "ethical review." Trial participants respond positively to his presence in the video, indicating that it conveys the study's professionalism and that their involvement in the research is valued.

The efficacy of using video to improve comprehension is still being evaluated. The Population Council is conducting a formal evaluation of the informed consent process in the Carraguard Phase 3 trial, which will include an assessment of whether the video improves comprehension and has an impact on individuals' willingness to participate in the trial. Anecdotal reports presented at the workshop suggested that study staff and trial participants find the video helpful, informative, and interesting; women like seeing what they will experience if they enroll in the trial and respond positively to the actress who narrates. According to study staff, however, some women find the video boring or repetitive, and some are frightened by the portrayal of the pelvic exam and the HIV test. Despite the extensive work invested in developing the Carraguard video and other supplemental materials, a number of concepts seem to re- main unclear to participants: why a placebo is used and how the microbicide's effectiveness will be determined if participants use condoms.

Developing a video can be a complex process, sometimes requiring a long lead time before a study begins, which can make it difficult to accommodate protocol changes. Video production can be especially complex in the case of multisite trials that may use diverse participants who speak different languages. Even for sites only in South Africa, the Carraguard video had to be produced in four languages (Xhosa, Tswana, Zulu, and English) to reflect the languages spoken at each site. Teams for all three trials that use video (Carraguard, MIRA, and Partners in Prevention) have also encountered challenges in using the videos as planned. Showing a video at all recruitment venues may not be feasible; attracting the attention of potential participants in busy clinic sites may be difficult; and bringing expensive projection equipment to the recruitment sites can be cumbersome or even dangerous.

Video technology offers exciting possibilities for facilitating recruitment and informed consent processes, particularly in large-scale efficacy trials, and ongoing evaluation is needed to identify how video can best be used. Such evaluations should consider not only whether use of a video improves prospective participants' comprehension but also should determine the extent to which video engages their interest, standardizes provision of information, and reduces the burden on study staff.

\section{ACASI}

The BOTUSA Project PREP trial was the only trial represented at the workshop that was planning to use audio computer-assisted self-instruction. As noted above, at the time of the workshop, the BOTUSA Project trial had not yet 
begun recruiting trial participants, so this system had been pilot-tested but not yet implemented.

The ACASI method employs a touchscreen computer application session designed to educate potential participants about the study. Information is presented in film clips with narrators talking through each screen. Participants can select the language they prefer to use from several choices. Some sections of the instruction, such as basic trial information, are required; others, such as information about HIV transmission, are optional (HIV prevention information is pervasive in Botswana). Participants can take as much time as they need and have the option of exploring a number of issues in depth. A self-test is included at the end of the session, and the results are reviewed with a counselor to clarify any issues that may be problematic, before signing the informed consent form. As with video technology, ACASI should be evaluated for its effectiveness as an informed consent tool along multiple dimensions.

\section{Providing Trial Information:}

\section{Audience and Tools}

One of the complexities of implementing a multistage informed consent process using diverse supplemental materials is determining what information should be presented to whom at which point in the process, and using which modes of communication. Workshop participants discussed these issues at length, and although no consensus was reached, a number of important points emerged. All trials conceptualized informed consent as a comprehensive process that engages the broader community as well as trial volunteers and participants. In addition to informing participants about trial procedures, risks, and benefits, it is crucial to be transparent with the community and provide information to reduce rumors, misunderstanding, and misinformation. As shown in the example in the box below, trials employ different materials and strategies for conveying information to their various constituencies.

The MIRA trial emphasizes several key messages in its community outreach: the purpose of the trial, the inclusion criteria, the need for participants to be able and willing to give their informed consent, and contact details. Trial staff members feel that the most important message to provide is the experimental nature of the trial and that it is not known whether the product works to prevent HIV transmission. Additional details of the study are provided dur-

\section{Carraguard trial outreach and informed consent tools}

\begin{tabular}{lll}
\hline Tool & When used & Purpose \\
\hline Flyers/posters & Before recruitment & $\begin{array}{l}\text { To present basic study information to attract potential } \\
\text { participants }\end{array}$ \\
Video & $\begin{array}{l}\text { Recruitment and/or } \\
\text { screening }\end{array}$ & $\begin{array}{l}\text { To present key themes and difficult concepts } \\
\text { To standardize information presented }\end{array}$ \\
Booklet & $\begin{array}{l}\text { Recruitment } \\
\text { Screening }\end{array}$ & $\begin{array}{l}\text { To supplement the informed consent form } \\
\text { with details and illustrations }\end{array}$ \\
& Ongoing consent & \\
Informed consent form & Screening & To provide required information as simply as \\
& & possible (bullets; short sentences) \\
Gel instructions & Enrollment & To present details of gel insertion and applicator collection
\end{tabular}


ing the screening and enrollment informed consent processes. The Soweto community in which one of the MIRA trial sites is located is also the setting for dozens of other clinical trials. In this context, the MIRA trial has identified a critical need to inform the community about the entire concept of informed consent and has contracted with a local radio station to present a monthly broadcast about research, clinical trials, and informed consent.

All trials represented at the workshop considered community outreach and informed consent to be part of a holistic process of partnership. Although developing general guidelines concerning what information should be provided to whom and at what time may be possible, determining the levels of information appropriate for various constituencies at different points in the process may be feasible and appropriate only in the context of specific trials and trial settings. (See the section above on community involvement and informed consent.)

\section{Explaining Difficult Concepts}

The workshop participants engaged in a lively brainstorming, discussion, and debate about which clinical trial concepts are the most challenging to convey. Of the wide range of topics mentioned, several were common to many trials and settings. For example, the broad notion of research and experimental scientific work was hard to grasp and unclear to many potential trial participants, and most study teams struggled with ways of describing and depicting the scientific process. Many people have difficulty understanding the concepts behind the use of placebos and randomization. Although some trial participants can describe and define placebos or randomization, few are able to articulate why they are used in clinical research. The uncertainty inherent in the scientific process can also be hard to convey, particularly in the context of clinical research where there is likely some indication that a product works but additional research—such as the current trial-is needed for definitive evidence. People's tendency to associate the medical establishment and scientific processes with facts and certainty is amplified by their urgent need for new products for the prevention and treatment of HIV/AIDS. Virtually everyone at the workshop was concerned about the issue of therapeutic misconception, especially against the backdrop of the acute need for new HIV prevention technologies and the implications for behavioral disinhibition.

During the third day of the workshop, a subset of participants explored different approaches to describing difficult concepts. Workshop organizers had requested informed consent and educational materials from a number of trials that were represented at the meeting and reviewed these informed consent forms, study booklets, flip charts, fact sheets, pamphlets, and videos prior to the workshop. This review, although not comprehensive, provides some concrete examples of conceptual approaches to presenting and describing the complex information and concepts associated with an HIV prevention trial (Bracken 2005).*

Some of the key points are highlighted below:

\footnotetext{
* These examples are being used in different trials and were developed based on different degrees of formative research and pilot testing. How effective they are at conveying information clearly to trial volunteers and participants is not known in every case, so these should not be considered at this time as "best practice."
} 
- Most of the materials reviewed include both text and visual images (drawings, pictures, and/or diagrams) to convey or reinforce particular concepts. The style of the printed materials varies; some materials use multiple colors for images and fonts, and others use color selectively to emphasize key terms or points. Interestingly, many materials developed for different trials and settings use red to highlight important concepts or words, although it is not clear whether the use of red in this way carries the intended meaning in all contexts.

- Most materials begin with a "problem statement," or broader rationale for undertaking the research and developing new approaches or products for HIV prevention. Most start with a description of HIV/AIDS, followed by a discussion of current methods to prevent transmission of the virus, including information about safer sex practices. Several of the materials highlight the limitations of current prevention strategies (for example, that the use of condoms is controlled by men) and acknowledge that consistent use of current approaches is not feasible for many people. Some of the materials also include other relevant public health messages.

- Some materials include a description of scientific processes, and emphasize the multiple stages of research conducted to determine product safety and efficacy. They describe where the current trial fits into this overall process.

- The concept of research, which may be unfamiliar to many potential trial partic- ipants, is conveyed through a range of images: test tubes and microscopes; a magnifying glass; clinic interiors; and doctors and scientists in white lab coats. Some workshop participants were skeptical about whether such images are meaningful to trial volunteers who have little or no experience or associations with items like microscopes. Researchers conducting the Carraguard Phase 3 trial noted that one of the IRBs had required them to include a "scientist in a white coat" at the end of the video to reinforce the experimental nature of the product and to itemize the risks and benefits of the trial for research participants.

- Randomization is explained by using images associated with chance, such as rolling dice or a lotto machine; a computer is depicted to underscore that no person decides whether a trial participant will

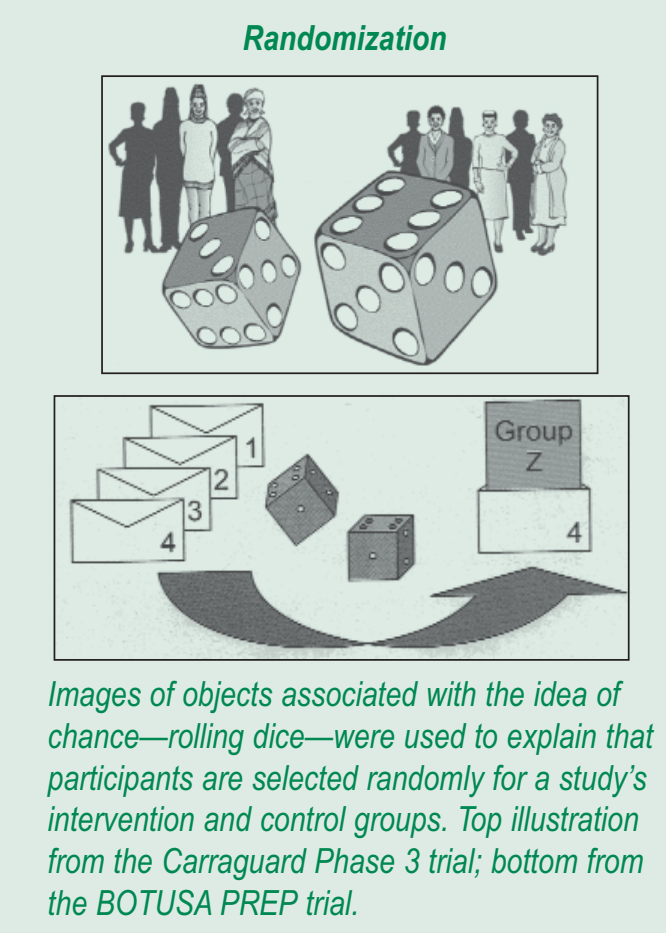


be in the intervention or control group. However, workshop participants acknowledged that finding a consistent way of illustrating this concept for studies with sites in multiple countries can be difficult.

- In describing a placebo, the descriptions in the materials emphasize that the study product and the placebo are identical

\section{Placebo}

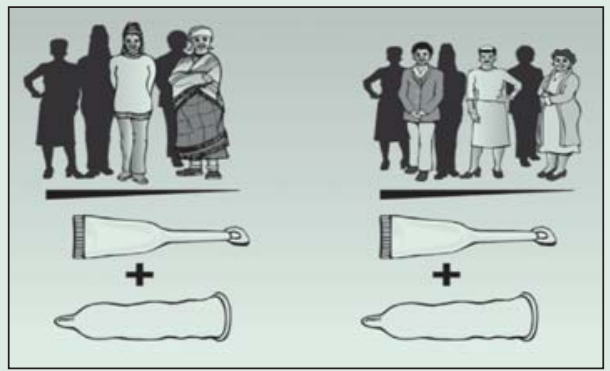

Drawings in the Carraguard Phase 3 video were used to emphasize that the product and the placebo look the same and are used in the same way but that the placebo is inactive.

except that the placebo is "inactive," or "doesn't have [name of active ingredient] in it," or that "one contains [the active ingredient] and one does not." One trial refers to the placebo throughout as the "comparison gel." Other suggested approaches to explaining the use of a placebo include using images of vitamin-enriched juice or milk, costume jewelry, or imitation products such as Coke ${ }^{\mathrm{TM}}$ and Diet Coke ${ }^{\mathrm{TM}}$. Specific analogies must be drawn from and tested in each setting to ensure that the example is clear and relevant.

- Different trials describe the study drug's or product's posited mechanism of action with varying degrees of complexity by saying that it: "blocks HIV," "acts as a barrier," or "protects us from getting sick by enabling our immune system to recognize and destroy the organism that causes disease."

- Most of the materials used either explicit or suggestive images for sensitive issues. For example, some materials used drawings of shoes or a pile of clothes to suggest sex, whereas others depicted a nude man and woman lying together (see box below). Some participants expressed concern that using explicit materials that may be taken home or seen by other people may stigmatize the study or the participants. One study team chose to include the illustration of a pelvic exam only on printed materials used at the clinic site but not in materials that participants took home.

- One particularly complex issue to convey is that of serodiscordance, a critical and potentially highly charged dimension of the Partners in Prevention HSV/HIV

\section{Sexual Activity}
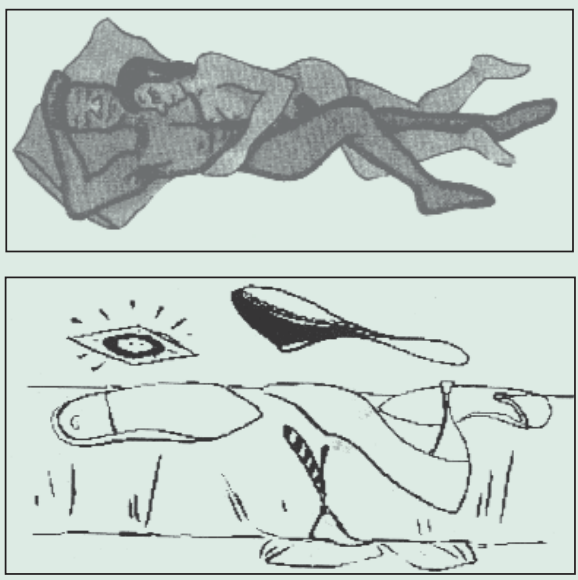

Depending on the study site, the materials in various Carraguard trials used explicit images (top-South Africa) or suggestive ones (bottom-Thailand) to suggest sex. 


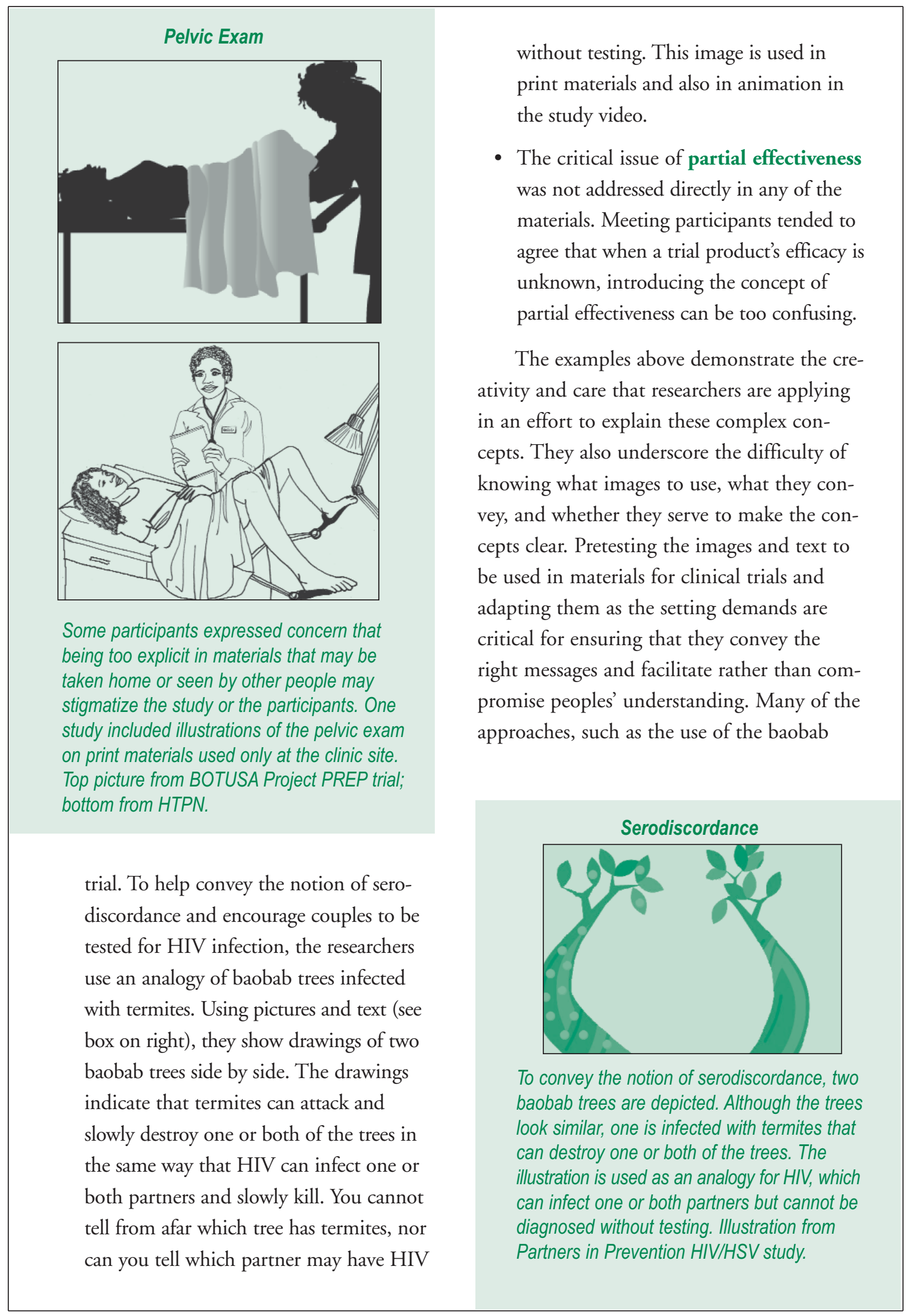


tree analogy, may be effective in some settings but would not be relevant in others. Workshop participants agreed that it is important to continue to experiment with different approaches and images for conveying complex concepts, to evaluate them rigorously, and to exchange information about what works.

\section{Training}

Ensuring that trial staff can and do use the materials developed for the informed consent process is essential for integrating them effectively into the trial. Even the best materials are of limited use if study staff do not use them appropriately and consistently. For example, the BOTUSA Project has developed a number of strategies to ensure the effective implementation of the informed consent process in the research clinic. These include training in good clinical practice, translation and back-translation of all materials, staff training in informed consent procedures, practice drills with observation, and quality-assurance observations during the study.

Implementing HPTN's comprehensive approach has also required training to familiarize staff with using various tools and approaches and additional work to develop standard operating procedures and ways of monitoring the informed consent process. Staff undergo a two-day training on informed consent, starting with a general review of informed consent requirements and the specific approach adopted for the trial. Staff then review the supportive materials, including a page-by-page review of the booklet. They engage in brainstorming and role-playing using visual aids, administering the comprehension assessment, and reviewing the consent forms. Based on results of monitoring, additional "booster" training may be added as a refresher or to emphasize particular elements of the informed consent process. As with all other elements of good clinical practice for trials, sufficient resources must be allocated in the trial budget for ongoing training.

HIV prevention trials are experimenting with a wide range of tools and approaches for conveying complex issues. Developing, producing and employing these tools can be costly. Evaluating the efficacy of different tools is important and requires the resources and the commitment of the broader trial staff and infrastructure. Not all of the current trial sponsors or trial staff have been willing to commit resources and staff time to such formal evaluation. 


\section{Assessing Comprehension}

\section{Many HIV prevention trials are currently grap- pling with how best to meas- ure potential participants' understanding of trial issues.}

How do adults learn? How should information about a trial be presented to ensure that a volunteer's consent is truly informed? Should comprehension of particular concepts and study procedures be considered essential where volunteers must demonstrate their understanding or they will not be allowed to enroll in the trial? How should those issues be determined? What methods should be used to assess comprehension and what are the advantages and disadvantages of each? How can information gleaned from such a process best be used for adapting and improving the informed consent process and materials? Workshop participants considered theory and practice in debating these issues.

\section{Adult Learning}

The field of adult learning posits a number of theories and approaches to understanding how adults learn. Based on research conduct-

\section{Communication Approaches}

Most effective Teaching others

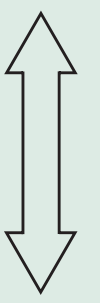
Immediate application in real situation Practice through doing Discussion Demonstration Audiovisual Reading

Least effective Lecture ed in developed countries, the relevance of these theories and approaches may vary depending on the respondent's culture, age, level of formal education, and gender. Even so, the field of adult learning offers a number of perspectives and insights useful to assessing informed consent.

Adult learning theory suggests that individuals understand and retain information differently depending on how it is presented. In general, people are apt to forget information they hear; they are more likely to remember information they see; and they are most likely to understand and remember information they use (see box below: Communication Approaches). Comprehension and recall are also strongly influenced by the level of abstraction of the information presented.

According to Bloom's commonly used taxonomy (Bloom 1956), three levels of learning are particularly relevant to the informed consent process: knowledge of factual information; comprehension (interpretation of information in the respondent's own words); and application of knowledge or generalization of knowledge to other situations (Moser 2005).

In developing an assessment approach, it is critical to consider carefully the types of questions that will elicit the relevant information and thought processes. Will a question measure the short-term recall of facts or the more sophisticated and nuanced concept of "understanding"? Knowledge questions elicit factual answers and test recall or the ability to recognize critical information. Comprehension questions require the potential participant to identify information about content and to translate that information into anoth- 


\section{Sample Assessment Questions}

Knowledge: From the list, choose the correct number of times you need to visit the clinic during the study.

Comprehension: Why are we testing this product? To see if it prevents HIV/AIDS or cures it? Explain the difference between "prevent" and "cure."

Application: Tell me what will happen before you have sex. Where will you keep the product? How will you use it? When will you apply it?

er form to display understanding of that information. Application questions can be used to explore the participant's ability to apply knowledge to solve problems. All three approaches can be useful for assessing informed consent. When feasible, combining methods and techniques may be the most comprehensive and productive approach.

\section{Quantitative or Qualitative Approaches}

Researchers designing informed consent assessments confront a choice about whether to employ primarily quantitative approaches, which use closed-ended questions (for example, true/false or multiple choice) or qualitative approaches, which feature open-ended questions. Closed-ended questions are generally better for eliciting specific information, one-word answers, or for checking facts. This approach has a number of advantages: it is relatively simple to administer, the evaluation is relatively objective, and less staff training is required. A quantitative approach has been used in HIV vaccine trials, including the AIDSVax trial, in which volunteers were administered a true/ false test on a number of key issues prior to signing the informed consent form.
However, for assessing comprehension of complex issues, such an approach can be limited. Closed-ended questions can create the illusion that the trial volunteer has understood information when all that is really being measured is his or her short-term ability to repeat what he or she has been told. Developing the questions and the overall instrument can present difficulties. Choosing the precise wording and terms to use is especially complicated for trials conducted at multiple sites and in more than one language. By their nature, true/false questions include incorrect statements that can confuse volunteers. Study staff have often expressed concern about voicing and repeating information that is not correct. As a result, true/false assessments tend to be skewed to "true" statements. Finally, the true/false approach is not familiar in many settings; it may confuse trial volunteers, and they may consider it impolite or inappropriate to tell the counselor or provider that a statement she or he has made is "wrong." Quantitative measures, while most objective, are minimally effective when used alone to elicit information about understanding of complex and varied issues.

In contrast, qualitative assessments that use open-ended questions generally encourage people to say more and reveal more clearly whether information has been understood. Qualitative assessments are better for helping to initiate meaningful discussion through which a volunteer's questions can be answered. Staff can also get a sense of whether a participant can apply information to deciding whether to participate in a clinical trial and to following the protocol. The open-ended approach allows the participant to respond in his or her own words in a dialogue consistent with the spirit of informed 
consent. However, such an approach is subjective in that it requires the staff to make judgments about a volunteer's level of understanding and eligibility to enroll in the trial, based on varied responses. Qualitative assessments require more extensive staff training and greater amounts of staff time and skill than the quantitative approach.

\section{What Do Participants Need to Know?}

Although a volunteer's full comprehension of all elements of a trial is the aim of informed consent efforts, achieving this level of understanding may not always be possible. As one speaker pointed out, a discussion paper from the Nuffield Council on Bioethics notes that "fully informed consent is unattainable" (NCB 2002). Workshop participants discussed and debated what level of understanding volunteers should be required to have in order to participate in a trial. How much information is enough for making an informed decision to enroll in and continue to participate in a trial? Are there particular issues that all volunteers must clearly comprehend in order to enroll? What are they and how should they be determined?

Although no clear consensus was reached at the workshop, participants considered a number of issues to be critical for trial volunteers to understand: the purpose of the research; the experimental nature of the trial; the uncertainty about the trial products' efficacy in preventing HIV infection; and the need to continue other risk-reduction practices during the course of the trial. Participants in all trials also were required to have some knowledge about the concepts of randomization, placebo, and blinding, as well as of key issues related to study procedures, risks, benefits, voluntarism, and confidentiality.
Issues that participants must comprehend may vary according to the specific product being tested. For example, in CONRAD's Phase 3 trial of the candidate microbicide cellulose sulfate, in which only women are enrolled, the comprehension assessment emphasizes the need to practice contraception. In a Phase 3 efficacy trial of the candidate HIV vaccine AIDSVax, in which male injecting drug users were enrolled, the comprehension assessment emphasized safe injection practices and included awareness of vaccine-induced seropositivity.

\section{Implementing Comprehension Assess- ments: Experiences from the Field}

Ongoing HIV prevention trials are using a number of approaches to assess comprehension as part of the informed consent process. These assessments generally are being conducted in an instrumental fashion for the purposes of the particular trial and its implementation, rather than as a way to contribute to a broader empirical understanding of the informed consent process.

The HPTN 035 trial is currently using an open-ended assessment consisting of eight items (see box on page 32: HPTN 035 Enrollment Informed Consent Comprehension Checklist) that reflect the required elements of informed consent according to the US Code of Federal Regulations (see box on page 6: Basic Elements of Informed Consent). Within each of these items are more specific elements, "must knows" that volunteers are required to answer correctly in order to be enrolled. The assessment is conducted in a conversational style. If, in the course of answering a particular question, a volunteer also answers another question, she is given credit for both responses. Interestingly, the 


\section{HPTN 035 Enrollment Informed Consent Comprehension Checklist, Version 1.0}

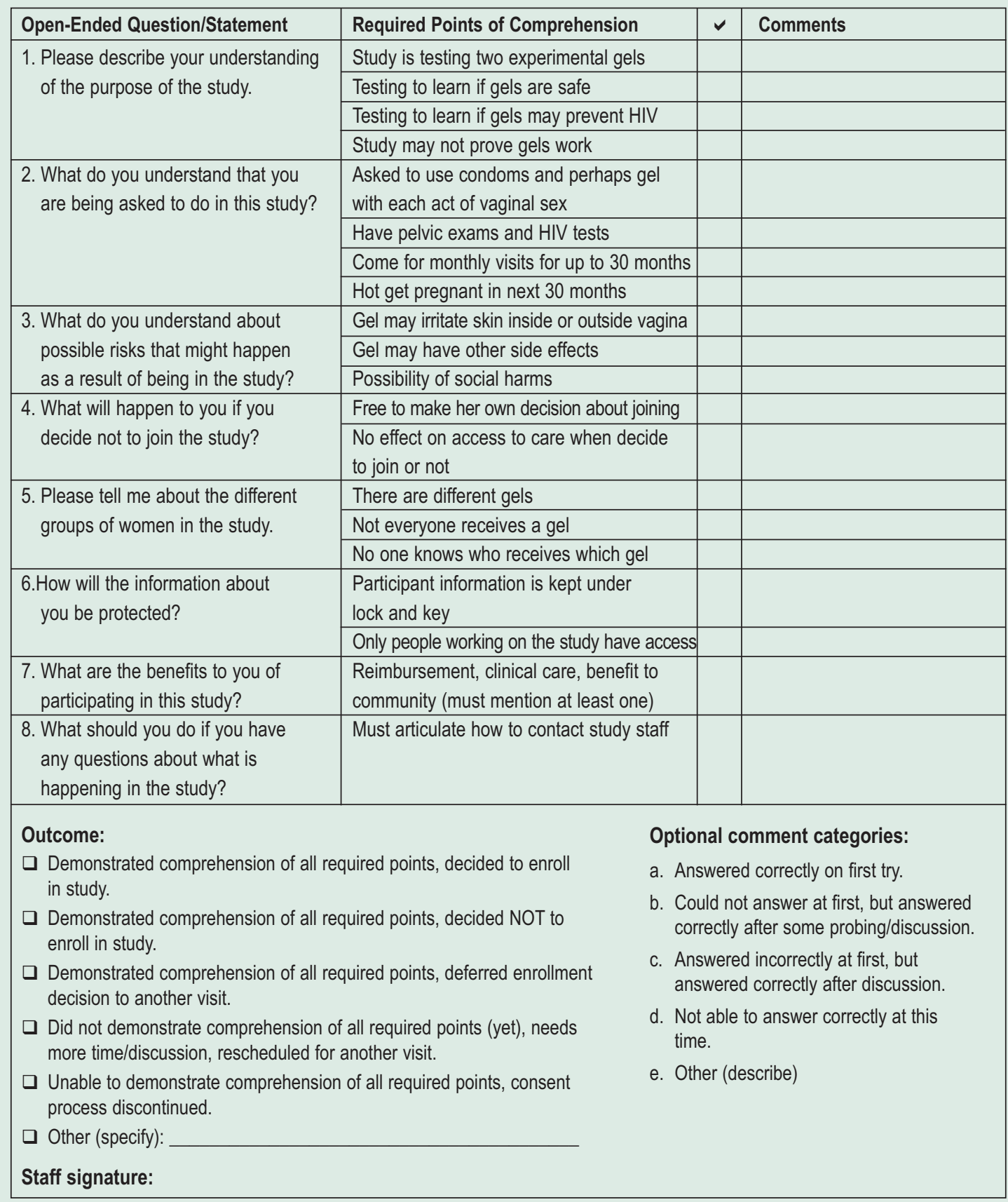

HPTN working group initially chose a closedended approach for its relative ease and consistency, but after considering its limitations, the group switched to an open-ended strategy. The assessment tool benefited from continuous in- put from the community and from pilot testing and adaptation at all of the trial sites. It is being used successfully at all of the sites to assess comprehension before women can enroll in the trial, and the team plans to use the same instru- 
ments for assessment among a random sample of trial participants throughout the trial.

CONRAD's Phase 3 cellulose sulfate trial also involves a conversational approach to the assessment of comprehension, using questions framed as "correct" and "incorrect." Staff in this trial assess comprehension at the enrollment informed consent session during which volunteers must answer five main questions correctly before signing the informed consent form. Volunteers do not need to answer in specific terms; the counselor makes a judgment about whether the woman demonstrates comprehension. If she does not answer a question accurately, staff will discuss and explain it further. If concerns remain about her comprehension of key issues, staff will schedule another appointment for further discussion if the volunteer wishes. The same tool will be used with trial participants every three months to check participants' understanding. Information will be repeated and reinforced during these sessions if necessary, but women will not be asked to leave the trial if they cannot answer correctly.

In the BOTUSA Project's tenofovir PREP trial, volunteers who wish to enroll in the study are required to take a comprehension test consisting of 20 true/false questions. Participants must answer 80 percent of the questions correctly, including two questions that relate to the unknown efficacy of the test product and the risk of HIV infection. If necessary or desired, this test can be taken again once. Informed consent is then administered orally, and a copy of the informed consent form is given to the participant. The test will be readministered every six months during the trial, and concepts that are not well understood will be reinforced at that time.
Meeting participants had varying views about how much information, support, and retesting should be available before a potential participant is deemed ineligible to enroll. In the HPTN 035 trial, a volunteer can return over the course of several days to continue the informed consent process. Other trials allow a volunteer to ask questions in order to clarify information and to be reevaluated a limited number of times before being judged ineligible for enrollment. For participants already enrolled, these assessment tools are not used to withdraw volunteers; rather they are used for evaluation, monitoring, and quality improvement.

Because such assessments can be interpreted as tests and can be intimidating to trial volunteers, several researchers suggested that trial staff present the assessment as a check to determine if the staff has done a good job of explaining the study rather than as a test for the participant. One researcher noted that participants are told, "We are not evaluating you; we are evaluating us."

\section{Staffing and Training}

A key component of informed consent implementation and assessment is staffing and staff training. As one speaker noted, the best informed consent tool, assessment, or process is only as good as the person or people charged with implementing it. As described above, open-ended approaches generally require more sophisticated and nuanced judgment on the part of staff and, therefore, necessitate considerable initial training as well as ongoing monitoring and support. Enrollment targets may create a disincentive for staff to determine that a trial volunteer does not understand the information well enough to enroll. One inves- 
tigator noted that this tension is acknowledged openly and that staff are advised that volunteers who have difficulty demonstrating their understanding for informed consent purposes are less likely to remain in the trial and, therefore, may not be suitable participants.

\section{Feedback and Adaptation}

Assessments of volunteers' understanding can provide important information for supplementing or adapting informed consent materials or approaches. In addition to determining an individual volunteer's eligibility, assessments can highlight areas that may need to be revised or adapted if volunteers consistently have difficulty understanding them. Supplemental materials, such as frequently asked questions, can be used to respond to new issues that emerge. It is important for trials to build in a process that allows for feedback and course correction using results of informed consent assessments, staff feedback, and contextual changes.
The open-ended approach, with its conversational mode that allows for discussion of questions and issues in respondents' own words, seems to be the best strategy for assessing the complex array of recall, comprehension, and application required for ensuring genuinely informed consent. Depending on the protocol, the individual, and the cultural setting, people may respond very differently to open-ended questions. Therefore, pretesting and adaptation of instruments are essential for producing suitable assessment tools for each trial setting. Identifying a set of "deal-breaker" topics that participants must clearly comprehend is critical. Assessments can be used to identify common problem areas to be addressed by modifying processes or developing supplemental materials. Although assessments that elicit more information and discussion are generally most useful for determining prospective participants' understanding, the constraints of time, availability of skilled staff, and other resources may restrict their use in practice. 


\section{Monitoring and Evaluation of the Informed Consent Process}

Formal evaluations of informed consent processes are necessary for determining whether the resources invested in materials, training, and implementation actually result in improvements of the informed consent process. As previously noted, few such evaluations have been undertaken in clinical research conducted in developing countries, particularly in prevention trials that enroll healthy people. Among the trials represented at the workshop, only the Population Council's Carraguard Phase 3 trial will include a formal evaluation of the informed consent process.

The workshop included a presentation of a recent review of research on improving informed consent (Flory and Emanuel 2004). The review was based on a broad search of Medline and other sources; it included 42 controlled trials of interventions that compared a "standard" consent process to an "enhanced" consent process and that measured understanding quantitatively. Of these studies, 30 were published in the formal literature and five were related to HIV/AIDS, although only one was conducted in a developing country. The clinical trials in which the informed consent evaluations were embedded included randomized controlled trials, longitudinal trials, and trials with nonrandom allocation for a range of diseases and interventions. Interventions to improve understanding included four main approaches that mirror those being used in some HIV prevention trials: multimedia presentations, includ- ing video; shorter, more readable forms; increased discussion time; and short quizzes used to confirm understanding and provide feedback on test results.

This review suggested that extended discussion with a counselor or nurse has the greatest effect on improving potential participants' understanding. Evidence for the efficacy of other interventions was mixed.

Although these findings are instructive, the degree to which they can be generalized to other settings, populations, and trials is uncertain. As described during the workshop, researchers conducting clinical trials continue to develop and incorporate a range of approaches into their informed consent processes. It is, therefore, important to evaluate rigorously the efficacy of these expanded informed consent processes in a range of trial types, populations, and contexts. Research designed to distinguish between participants' memorization of facts and their comprehension of the information provided is especially valuable. Such research is particularly important for the conduct of studies in developing countries in light of the paucity of information available about such interventions and the growing attention to study processes and research ethics-including informed consent.

One speaker noted that any such evaluation depends on gathering high-quality data, and he enumerated several key elements for doing so (Sugarman 2005). Most important, the evaluation should be independent and the results kept confidential. The process should not interfere with the clinical research process, 
should pose minimal burden for staff, and should be practical and simple (Lavori et al. 1999; Sugarman et al. 2005). The research team and sponsor must support the evaluation. A sound study design is essential, and teasing out the complexities of participants' recall, comprehension, decisionmaking, and potentially varied sources of information and experience can be challenging (Sachs et al. 2003). Finally, staff must be trained in implementing the informed consent study and in interpreting and applying the results.

\section{Cost and Cost-effectiveness}

Costs associated with an informed consent process are just one dimension of a broader ethical debate on justice surrounding the conduct of research in resource-poor settings that also includes discussions of standard of care and access to the product being tested.

Although costs of even an enhanced informed consent process are likely to be only a small part of the budget of a clinical trial, they may be significant and must be weighted against other investments and considerations in managing the research process, protecting the welfare of participants, and communicating the results to key stakeholders. Evidence of costeffectiveness is an important factor in convincing sponsors to continue to support investment in informed consent materials and processes (Townsend and RamaRao 2005).

Evaluating cost-effectiveness requires determining a standard for effectiveness that factors in both financial and nonfinancial costs. Assessment processes must clarify the roles of various stakeholders in defining effec- tiveness and covering the costs of informed consent. Defining "costs" will likely vary across different actors - the participants, the researchers, the community, and the research institution. The standard for effectiveness may vary according to a number of factors. For example, the understanding of participants in experimental research should be higher than that of those receiving treatment: the higher the potential risk, the more rigorous the measure of comprehension; and the more vulnerable the participant, the greater the concern about protections afforded by informed consent. In considering cost, it is important to acknowledge that current research is taking place in a historical context of poorly conducted trials that created a legacy of exploitation and suspicion.

Evaluating informed consent processes is important, but it is also challenging and potentially controversial. Virtually all trials fall short of "perfect" informed consent. As evidence presented at the workshop indicates, certain issues remain difficult for people to understand despite concerted and creative efforts to explain them. Therefore, evaluating informed consent processes - and disseminating the results — can be risky for trial sponsors. Given that perfection is unlikely to be achieved, when is the investment in informed consent sufficient? How willing will sponsors be to disclose the less-than-perfect results of such an evaluation? How can findings about best practices in informed consent be shared? Navigating these questions may present challenges as great as those of conducting and evaluating informed consent itself. 


\section{Conclusion and Recommendations}

Several primary themes emerged from the presentations and wide-ranging discussion at the workshop. First, HIV prevention trials are incorporating expanded informed consent processes that employ innovative materials and approaches. This commitment reflects researchers' recognition of the complexity of ensuring informed consent and of their ethical responsibility to do so. Second, the role of community is widely recognized as integral to research and specifically to informed consent. The degree to which these trials include community members and leaders in the informed consent process is striking. The community is provided with information about the trial, and community input is solicited about informed consent approaches and in the review of materials and strategies. Finally, workshop participants agreed that it is critical to demonstrate through empirical evidence that expanded informed consent processes such as those presented enhance the conduct of a clinical trial as well the informed consent of trial participants.

Although many of the trials represented at the workshop are investing considerable time and effort to improve the informed consent process, this practice is not the norm in clinical research. For many investigators, staff, and trial participants, informed consent remains a formality reduced to a form and a signature. Empirical evidence demonstrating how to improve informed consent and the benefits of a comprehensive informed consent program may not only help to convince researchers in other fields to adopt such an approach but also can provide oversight bodies like ethics committees with better standards for judging the adequacy of informed consent processes.

A range of potential benefits of an expanded approach has been posited. Participants' improved initial comprehension of the study requirements may lead to efficiencies by improving ratios for screening/eligibility and eligibility/enrollment. Greater initial comprehension, reinforced throughout the trial, may also result in improved continued comprehension of and adherence to study requirements during the trial and reduced therapeutic misconceptions or behavioral disinhibition. As noted above, gathering empirical evidence to demonstrate the value of such an approach is important and can be achieved by ongoing testing of participants' comprehension, by monitoring community responses to the study, and by documenting participants' adherence to the study protocol. Such evidence can inform adaptation and improvements of the informed consent process; it can be used to justify to investigators, communities, trial participants, and sponsors the effort, time, and cost associated with developing and implementing a comprehensive approach. Several workshop participants noted the importance of justifying continued investment and experimentation in informed consent among trial sponsors and within large international organizations that sponsor research. Rigorous evaluation of informed consent processes can provide evidence to show whether they improve the 
overall conduct of the trial as well as its ethical dimensions.

Staff and researchers should continue to share information across studies regarding specific strategies for presenting information and for maximizing and assessing participants' comprehension. In addition to building evidence for continued investment, as described above, such exchange also can contribute to resolving common challenges, from decisions about what media and strategies to use to developing staff-training curricula to selecting specific approaches for conveying complex concepts such as randomization and use of placebos. Several workshop participants thought that determining which tools and approaches work and have the greatest impact would be useful so that researchers can focus on those. Others cautioned that it is unlikely that there is one answer to this question and that research will likely point to a range of valuable approaches that can be deployed according to the setting, the trial, and the population.

Several participants suggested that the design and results of formative research should be treated as discrete and important research findings rather than simply as an instrumental way to inform trial design. This approach would contribute to these findings being shared and used across trials and increase overall knowledge essential to the conduct of HIV prevention research. It could also help elevate the role that such formative research plays within trials in developing informed consent and other trial processes.

Participants attending the workshop were struck by the opportunities presented by the "natural experiment" now underway as many HIV prevention trials experiment with innovative approaches to informed consent. Many expressed interest in continuing to share information and develop strategies for evaluating specific informed consent tools and overall processes, possibly through an ongoing working group. A number of participants were particularly keen to look at the comprehension assessments in greater depth to share strategies and ideas.

Specific recommendations for follow-up actions that emerged from the meeting include:

- forming a working group among staff and researchers involved in informed consent in HIV prevention trials to identify specific research priorities and strategies; to exchange information and ideas; to look closely at comprehension assessments; and to continue to develop research design and advocacy strategies for conducting overall evaluations of informed consent processes in ongoing trials;

- convening a follow-up workshop for study staff and researchers in order to address informed consent with activists and community members;

- advocating for formative research to be analyzed and disseminated more widely; and

- continuing to capitalize on the energy, creativity, and commitment being brought to this field.

Finally, although participants acknowledged that some aspects of informed consent remain very difficult, one suggested that informed consent be seen as a kind of "standard of care." The community has a responsibility to continue to evolve and improve approaches and standards for informed consent, even if they may never be perfect. 


\section{References}

Abdool Karim, Q. 1998. "Informed consent for HIV testing in a South African hospital: Is it truly informed and truly voluntary?" American Journal of Public Health 88(4): 637-640.

Attafuah, John. 2005. "The informed consent advocate." Presentation at the Population Council/Family Health International Workshop on Informed Consent in HIV Prevention Trials, New York, 16-18 May.

Bartholow, B.N. et al. 1997. "Assessment of the changing willingness to participate in phase III HIV vaccine trials among men who have sex with men." Journal of Acquired Immune Deficiency Syndromes and Human Retrovirology 16(2): 108-115.

Bloom, B.S. (ed). 1956. Taxonomy of Educational Objectives: The Classification of Educational Goals: Handbook I, Cognitive Domain. New York: Longmans, Green.

Bracken, H. "Communicating complex concepts." Presentation at the Population Council/Family Health International Workshop on Informed HIV Prevention Trials, New York, 16-18 May.

Chaikummao, S. 2005. "Men in microbicide trials: Carraguard couples study." Presentation at the Population Council/Family Health International Workshop on Informed Consent in HIV Prevention Trials, New York, 16-18 May.

Chigwanda, M. 2005. "Community influence on informed consent." Presentation at the Population Council/Family Health International Workshop on Informed Consent in HIV Prevention Trials, New York, 16-18 May.

Chillag, K. 2005. "Informed consent process: The Botswana Oral Tenofovir Prophylaxis Trial." Presentation at the Population Council/Family Health International Workshop on Informed Consent in HIV Prevention Trials, New York, 16-18 May.

Coletti, A.S. 2005. "HPTN 035 informed consent comprehension assessment." Presentation at the Population Council/Family Health International Workshop on Informed Consent in HIV Prevention Trials, New York, 16-18 May.

Coletti, A.S. et al. 2003. "Randomized, controlled evaluation of a prototype informed consent process for HIV vaccine efficacy trials." Journal of Acquired Immune Deficiency Syndromes 32(2): 161-169.

Council of Europe. 1997. Convention for the Protection of Human Rights and Dignity of the Human Being with Regard to the Application of Biology and Medicine: Convention on $\mathrm{Hu}-$ man Rights and Biomedicine. European Treaty Series No. 164. 4. Oviedo, Spain, April 1997. <http://conventions.coe.int/Treaty/en/Treaties/ Word/164.doc>. Accessed 7 March 2006.

De Kock, A., M. Marumo, and B. Friedland. 2005. "Carraguard Phase 3 Trial: Developing and implementing a video." Presentation at the Population Council/Family Health International Workshop on Informed Consent in HIV Prevention Trials, New York, 16-18 May.

Dickert, N. and C. Grady. 1999. "What's the price of a research subject? Approaches to payment for research participation." New England Journal of Medicine 341(3): 198-203.

Downs, J. 2005. "Risk perception and decisionmaking." Presentation at the Population Council/Family Health International Workshop on Informed Consent in HIV Prevention Trials, New York, 16-18 May.

Flory, J. and E. Emanuel. 2004. "Interventions to improve research participants' understanding in informed consent for research: A systematic review." Journal of the American Medical Association 292(12): 1,593-1,601.

Fortney, J.A. 1999. "Assessing recall and understanding of informed consent in a contraceptive clinical trial." Studies in Family Planning 30(4): 339-346.

Friedland, B. 2005. "Report from an international workshop on informed consent in HIV pre- 
vention trials." The Microbicide Quarterly 3(2): 13-16.

Global Campaign for Microbicides. 2005. Rethinking the Ethical Roadmap of Clinical Testing of Microbicides: Report on an International Consultation. Washington, DC: Global Campaign for Microbicides.

Hantman, J. and M. Gottemoeller. 2004. Mobilizing for Community Involvement: Report from a Dialogue in Southern Africa. Washington, DC: Global Campaign for Microbicides.

Heise, L., C.E. McGrory, and S.Y. Wood. 1998. Practical and Ethical Dilemmas in the Clinical Testing of Microbicides: A Report on a Symposium. New York: International Women's Health Coalition.

International AIDS Society. 2005. "Building collaboration to advance HIV prevention: Global consultation on tenofovir pre-exposure prophylaxis research." Geneva, September. $<$ http://www.iasociety.org/images/upload/ 888.pdf $>$.

International Conference on Harmonisation of Technical Requirements for Registration of Pharmaceuticals for Human Use (ICH). 1996. ICH Harmonised Tripartite Guideline: Guideline for Good Clinical Practice E6(R1), section 4.8.9. <http://www.ich.org/LOB/ media/MEDIA482.pdf>. Accessed 7 March 2006.

Kilmarx, P., G. Ramjee, D. Kitayaporn, and P. Kunasol. 2001. 'Protection of human subjects' rights in HIV-preventive clinical trials in Africa and Asia: Experiences and recommendations." AIDS 15(S5): S73-S79.

Lavori, P.W., J. Sugarman, M.T. Hays, and J.R. Feussner. 1999. "Improving informed consent in clinical trials: A duty to experiment." Controlled Clinical Trials 20(2): 187-193.

Leach, A. et al. 1999. "An evaluation of the informed consent procedure used during a trial of a Haemophilus influenzae type B conjugate vaccine undertaken in the Gambia,
West Africa." Social Science \& Medicine 48(2): 139-148.

MacQueen, K.M. et al. 2001. "What is community? An evidence-based definition for participatory public health." American Journal of Public Health 91(12): 1,929-1,938.

Mariner, W. 2003. "Taking informed consent seriously in global HIV vaccine research." Journal of Acquired Immune Deficiency Syndromes 32(2): 117-123.

Moodley, K. 2005. "The impact of participant remuneration on informed consent." Presentation at the Population Council/Family Health International Workshop on Informed Consent in HIV Prevention Trials, New York, 16-18 May.

Moser, F. 2005. "Checking for levels of competence." Presentation at the Population Council/Family Health International Workshop on Informed Consent in HIV Prevention Trials, New York, 16-18 May.

Mujugira, A. 2005. "HSV-2/HIV transmission study: Recruitment and informed consent issues with HIV-discordant couples." Presentation at the Population Council/Family Health International Workshop on Informed Consent in HIV Prevention Trials, New York, 16-18 May.

National Commission for the Protection of Human Subjects of Biomedical and Behavioral Research (NCPHSBBR). 1979. The Belmont Report: Ethical Principles and Guidelines for the Protection of Human Subjects of Research. DHEW publication no. (OS) 78-0012. Washington, DC: US Government Printing Office. <http://history.nih.gov/laws/pdf/ belmont.pdf>. Accessed 7 March 2006.

Nuffield Council on Bioethics (NCB). 2002. The Ethics of Research Related to Healthcare in Developing Countries. London: NCB.

Nuremberg Code. 1949. Trials of War Criminals before the Nuremberg Military Tribunals Under Control Council Law No. 10. Nuremberg, October 1946-April 1949, vol- 
ume 2. Washington, DC: US Government Printing Office, pp. 181-182.

Office of the Federal Register (OFR). 2002. US Federal Register, Code of Federal Regulations, General Requirements for Informed Consent, Title 45 (Public Welfare) Part 46 (Protection of Human Subjects), sec. 116. Washington, DC: OFR. <http://a257.g.akamaitech.net/7/ 257/2422/12feb20041500/edocket.access.gpo. gov/cfr_2004/aprqtr/21cfr50.20.htm>. Accessed 7 March 2006.

Participants in the 2001 Conference on Ethical Aspects of Research in Developing Countries. 2002. "Fair benefits for research in developing countries." Science 298(5,601): 2,133-2,134.

Pennington, B. 2005. "Informed consent challenges." Presentation at the Population Council/Family Health International Workshop on Informed Consent in HIV Prevention Trials, New York, 16-18 May.

Préziosi, M.-P. et al. 1997. "Practical experiences in obtaining informed consent for a vaccine trial in rural Africa." New England Journal of Medicine 336(5): 370-373.

Ramjee, G. et al. 2000. "Challenges in the conduct of vaginal microbicide effectiveness trials in the developing world." AIDS 14(16): 2,553-2,557.

Rivera, R., J. Reed, and D. Menius. 1992. "Evaluating the readability of informed consent forms used in contraceptive clinical trials." International Journal of Gynecology \& Obstetrics 38(3): 227-230.

Rivera, R. et al. 2004. Research Ethics Training Curriculum for Community Representatives. Durham, NC: Family Health International.

Sachs, G.A. et al. 2003. "Conducting empirical research on informed consent: Challenges and questions." IRB: Ethics \& Human Research Supplement 25(5): S4-S10.
Singh, J. 2005. "An overview of the challenges implicit in facilitating informed decisionmaking amongst research participants in the developing world." Presentation at the Population Council/Family Health International Workshop on Informed Consent in HIV Prevention Trials, New York, 16-18 May.

Sugarman, J., P.W. Lavori, M. Boeger, C. Cain, R. Edson, V. Morrison, and S.S. Yeh. 2005. "Evaluating the quality of informed consent." Clinical Trials 2(1): 34-41.

Sugarman, J. 2005. "Informed consent: What should we be evaluating and why?" Presentation at the Population Council/Family Health International Workshop on Informed Consent in HIV Prevention Trials, New York, 16-18 May.

Townsend, J. and S. RamaRao. 2005. "The costs of informed consent." Presentation at the Population Council/Family Health International Workshop on Informed Consent in HIV Prevention Trials, New York, 16-18 May.

Joint United Nations Programme on HIV/AIDS (UNAIDS). 2006. "Creating effective partnerships for HIV prevention trials: Report of a UNAIDS Consultation, Geneva 20-21 June 2005.” AIDS 20(6): W1-W11.

Weijer, C. and E.J. Emanuel. 2000. "Protecting communities in biomedical research." Science 289(5,482): 1,142-1,144.

Woodsong, C. and Q. Abdool Karim. 2005. “A model to enhance informed consent: Experiences from the HIV Prevention Trials Network." American Journal of Public Health 95(3): 412-419.

World Medical Association (WMA). 1964. World Medical Association Declaration of Helsinki: Ethical Principles for Medical Research Involving Human Subjects. Helsinki: WMA. 


\section{Glossary}

\section{ACASI}

Audio computer-assisted self-interviewing, a datacollection technique in which the respondent uses headphones connected to a laptop computer to listen to questions that have been digitally recorded and keys his or her responses directly into the computer. Because of the privacy that it provides, this methodology, developed at Research Triangle Institute, has proved to be a successful means of gathering sensitive or personal information.

\section{Acyclovir}

An antiviral agent used orally or topically to treat herpes infections of the skin, lip, and genitals; herpes zoster (shingles); and chickenpox. Used in treatment of herpes simplex virus type 2 (HSV2 ), acyclovir decreases the intensity and duration of outbreaks but does not eradicate the infection.

\section{$\operatorname{AIDSVax}^{\circledR}$}

An experimental vaccine developed by the biotechnology company VaxGen for the potential prevention of transmission of HIV infection. Made with genetically engineered proteins similar to a protein on the outer coat of the virus, the vaccine was intended to stimulate the immune system to generate antibodies to the gp120 portion of the virus. In the first largescale human trials of a vaccine designed to prevent transmission of HIV infection, the vaccine did not prevent transmission in study populations in North America and Europe (results released in February 2003) and Thailand (results released in November 2003).

\section{Antiretrovirals}

Chemical agents that are destructive to retroviruses either by disabling them or by preventing them from multiplying. Antiretrovirals are used to treat HIV/AIDS; different classes of antiretroviral drugs act at different stages of the HIV life cycle and are often used in combination.

\section{Behavioral disinhibition}

Risk-taking behavior; for example, an increase in high-risk sexual behavior that is based on perceived safety or protection due to use of condoms. In a clinical trial, a participant might feel protected by the test product and engage in risky behavior.

\section{BOTUSA Project}

A collaboration between the Botswana Ministry of Health and the Global AIDS Program (GAP) of the United States Centers for Disease Control and Prevention (CDC). The BOTUSA Project provides technical assistance, consultation, and funding; implements programs; and conducts research with the Botswana government and other local and international partners for prevention, care and support, and surveillance of HIV/AIDS, tuberculosis, and sexually transmitted diseases.

\section{BufferGel ${ }^{\mathrm{TM}}$}

A candidate vaginal microbicide developed by ReProtect; an acid buffer that keeps the vagina acidic even in the presence of semen and creates a physical barrier that stops or slows down the passage of pathogens into the vaginal and cervical walls. BufferGel is currently undergoing acceptability, safety, and effectiveness trials; it is expected to work as a contraceptive and may protect against HIV, HPV, HSV, chlamydia, and gonorrhea.

\section{Carraguard $^{\circledR}$}

A candidate microbicide gel, developed by the Population Council, made from carrageenan (a substance derived from seaweed); an attachment inhibitor that provides a physical barrier between pathogens and vulnerable cells in the cell wall (epithelium) of the vagina. Laboratory tests have shown that Carraguard (formerly known as PC-515) blocks infection by HIV, 
HSV-2, HPV, and gonorrhea both in vitro and in vivo and does not have contraceptive properties. The Population Council is currently conducting a large-scale Phase 3 efficacy and safety trial of Carraguard in South Africa to learn if it prevents sexual transmission of HIV.

\section{Cellulose sulfate (CS)}

A candidate vaginal microbicide developed by CONRAD; cellulose sulfate (CS) is an attachment inhibitor that provides a physical barrier between pathogens and vulnerable cells.

Preclinical trials showed the potential of CS to act as an effective guard against both unwanted pregnancy and STIs, including HIV. Currently, two safety and efficacy trials of CS are being conducted by Family Health International (FHI) and CONRAD.

\section{$\mathrm{CAB} / \mathrm{CAG}$}

Community advisory board or group, a group composed of diverse volunteers from a community_including activists and advocates, local professionals, and/or study participants - to provide input into clinical trials taking place in the community. The primary role of a $\mathrm{CAB} / \mathrm{CAG}$ is to ensure sensitivity to local context and inclusion of community input into the research process. CABs/CAGs provide an explicit opportunity for those affected by research to contribute to its development, implementation, and evaluation.

\section{CONRAD}

A research organization dedicated to improving reproductive health, particularly in developing countries where the need is greatest, by supporting the development of better, safer, and more acceptable methods for preventing pregnancy and the spread of sexually transmitted infections, including HIV/AIDS. CON$\mathrm{RAD}$ is currently conducting Phase 3 clinical trials of cellulose sulfate as a vaginal microbicide.

\section{Diaphragm}

A contraceptive device; a dome-shaped cup made of thin, flexible rubber that fits over the cervix and acts as a barrier to prevent sperm from entering the uterus by blocking the cervix. To increase protection, a spermicide is put into the diaphragm and along its edges before insertion. Currently, a trial is underway in South Africa and Zimbabwe to test the effectiveness of the latex diaphragm used with a lubricant for preventing heterosexual transmission of STIs, including HIV, among women (see MIRA).

\section{Effectiveness}

The extent to which an intervention or substance produces a desired effect under field-use conditions or conditions approximating field use; the ability to produce a specific result or to exert a specific measurable influence. (See also Efficacy.)

\section{Efficacy}

The ability of an intervention or substance to produce the desired beneficial effect in expert hands and under ideal circumstances; in pharmacology, the ability of a drug to produce the desired therapeutic effect. (See also Effectiveness.)

\section{Ethics committee}

Often called an institutional review board (IRB), a committee or other group formally designated by an institution to review, to approve the initiation of, and to conduct periodic review and oversight of research involving human participants. (See also IRB.)

\section{Formative research}

Research that is conducted in a community before a trial, project, or intervention is designed and implemented in order to help researchers to identify and understand the interests, characteristics, behaviors, attitudes, and needs of the tar- 
get population(s); to design research, programs, services, or products that are responsive to the needs of the target population(s); to identify barriers; to tailor messages; and to ensure that programs are feasible and acceptable to the study community. Methodologies can include surveys, focus-group discussions, in-depth interviews, use of key informants, participant observation, or other community assessments.

Participation of stakeholders in formative research contributes to producing a higherquality research project by maintaining focus on issues important to the community.

\section{GCP}

Good clinical practice, an international ethical and scientific quality standard for the design, conduct, performance, monitoring, auditing, recording, analysis, and reporting of clinical trials intended to ensure the integrity and validity of clinical data upon which product approvals are based and to help protect the rights, safety, confidentiality, and welfare of human subjects.

\section{HIVNET}

HIV Network for Prevention Trials, an international network of clinical trial sites, funded by the United States National Institutes of Health (NIH) from 1993-99 for conducting trials designed to evaluate the safety and efficacy of promising interventions to prevent sexual, perinatal, and parenteral transmission of HIV infection, using HIV seroincidence as the primary endpoint. Although they were originally established to focus on HIV vaccines, the interventions evaluated by HIVNET also encompassed topical microbicides, treatment of sexually transmitted diseases, prophylaxis to prevent mother-to-child transmission of infection, and behavioral risk-reduction strategies.

\section{HIV serodiscordance}

A situation in which one partner in a couple is infected with HIV and the other is uninfected.

\section{HIV seroconcordance}

A situation in which both partners in a couple are of the same HIV serostatus-either both are HIV-positive (infected with HIV) or both are HIV-negative (not infected with HIV).

\section{HPTN}

HIV Prevention Trials Network, a worldwide collaborative clinical trials network that develops and tests the safety and efficacy of nonvaccine interventions designed to prevent the transmission of HIV. Building on experience gained and relationships established as part of HIVNET (see above) and established in 1999 by the Division of AIDS (DAIDS) of the National Institute of Allergy and Infectious Diseases (NIAID), part of the United States National Institutes of Health (NIH), the HPTN works through an international network of scientists and investigators in partnership with a leadership group from three US-based institutions.

\section{$\mathrm{ICH}$}

The International Committee on Harmonisation of Technical Requirements for Registration of Pharmaceuticals for Human Use, a project that brings together the regulatory authorities of Europe, Japan, and the United States with experts from the pharmaceutical industry to discuss scientific and technical aspects of product registration. The purpose of the committee is to recommend ways to better interpret and apply technical guidelines and requirements for product registration in order to reduce duplication of testing during the development of new medicines to make economical use of resources, and to eliminate unnecessary delay in development and availability of new medicines, while maintaining regulatory obligations and safeguards on quality, safety, and efficacy to protect public health.

\section{IRB}

Institutional review board, a board, committee, or other group formally designated by an insti- 
tution to review, approve, and conduct periodic review of biomedical research involving human beings. An IRB's membership should reflect a diversity of scientific and nonscientific capacities and disciplines. In accordance with the US Food and Drug Administration's and US Office of Human Research Protections regulations, an IRB reviews research protocols and related materials (for example, informed consent documents and investigator brochures) and has the authority to approve, require modifications to (to secure approval), or disapprove research. The primary purpose of such review is to assure the protection of the rights and welfare of human participants in research.

\section{Key informant(s)}

Local individual(s) who can provide important information about the community and help researchers understand the study population and cultural environment. They are knowledgeable, observant, and articulate and often have special knowledge or understanding on topics of special interest. Key informants can help researchers understand phenomena that may not be obvious to an outsider.

\section{Longitudinal study}

A study designed to follow subjects forward through time.

\section{MCC}

Medicines Control Council of South Africa, a statutory body established in the Medicines and Related Substances Control Act 101 of 1965 to oversee the regulation of medicines in South Africa. The Council is appointed by the Minister of Health, and its main purpose is to safeguard and protect the public by ensuring that all medicines sold and used in South Africa are safe, therapeutically effective, and consistently meet acceptable standards of quality.

\section{MDP}

The Microbicides Development Programme, a partnership formed to develop vaginal microbicides for the prevention of HIV transmission. The MDP is funded by the UK Department for International Development (DFID) and administered by the Medical Research Council Clinical Trials Unit and Imperial College, London. It brings together academic institutions in the North and South, nonprofit organizations, and pharmaceutical companies.

\section{Mechanism of action}

The way a drug works or produces its biological effect.

\section{Medline}

An electronic/online database for scientific publications operated by the National Library of Medicine (NLM), part of the US government's National Institutes of Health.

\section{Microbicides}

A range of products, potentially in gel, cream, film, or suppository form, being developed to prevent the transmission of HIV and other sexually transmitted infections when applied topically.

\section{MIRA}

Methods of Improving Reproductive Health in Africa; a multisite randomized controlled trial being conducted in South Africa and Zimbabwe to determine the acceptability, feasibility, and effectiveness of the latex diaphragm used with a lubricant in preventing heterosexual transmission of HIV and other sexually transmitted infections among women. Combining a physical barrier that covers the cervix with a spermicide/microbicide is expected to enhance protection against transmission of STIs, including HIV, and to prevent pregnancy. 


\section{Partial effectiveness}

A term that refers to estimates of effectiveness of infection-prevention products ranging from 40 to 70 percent; the effectiveness of initial products such as microbicides and vaccines are expected to be considerably lower than the effectiveness of condoms used correctly and consistently (98 percent). A product such as a vaccine or microbicide may be effective only some of the time or only for some users, or both.

\section{Participant advisory group}

A group comprised of volunteers who are participants in a research project. Similar to a community advisory board or group, a participant advisory group is a formal mechanism that enables research participants to provide feedback to the research team and that is convened to ensure that participants' needs for support and information are addressed.

\section{Partners in Prevention}

A study currently being conducted by the University of Washington School of Medicine at sites in Africa to determine whether suppressing genital herpes can significantly reduce HIV transmission. The Phase 3 randomized placebocontrolled trial is being conducted among HIVdiscordant couples and is the first to evaluate whether transmission of HIV-1 can be reduced by treating genital herpes with acyclovir, a widely used and generically available medication; researchers theorize that the treatment could reduce HIV transmission by 50 percent.

\section{Phase 1 Trials}

Also known as safety trials, Phase 1 clinical trials are conducted in a small group (generally in the range of 20-80 individuals) of healthy participants at low risk of infection who are monitored carefully for any evidence of adverse effects of the intervention or treatment. Sometimes, where the drug being investigated is intended for use among people with a particular disease, patients with the disease may participate. The objective of Phase 1 trials is to determine the metabolic and pharmacological actions of the drug upon human subjects and to assess its safety, with the ultimate goal of obtaining sufficient information about the drug's effects to permit the design of valid Phase 2 studies. Phase 1 trials often include dosing assessments to determine optimal or threshold concentrations of the active agent for safety and potential effectiveness.

\section{Phase 2 Trials}

Phase 2 trials expand initial safety (Phase 1) trials to include a larger number of participants (no more than several hundred) who are at higher risk and who more closely approximate the people who are likely to participate in future efficacy trials. Phase 2 trials, therefore, gather data about safety among the potential users of a product or treatment and help to determine any short-term side effects or risks associated with the drug or treatment. In some cases, Phase 2 trials are also used to establish appropriate doses of medications or treatments.

\section{Phase 3 Trials}

Also known as efficacy (or effectiveness) trials, these are clinical trials designed to answer the question: Does this product or intervention work? The question can concern treating or preventing the condition or disease being studied. At this level, the new product or treatment is administered to a large number of participants (usually several hundred to several thousand) in different clinical settings to determine its safety and efficacy. When these studies are completed and the sponsor believes that the product is safe and effective under specific conditions, the sponsor applies to the Food and Drug Administration or other national regulatory authority for approval to market the drug.

\section{Phase 4 Trials}

If Phase 3 clinical trials establish adequate safety and effectiveness or efficacy of an intervention product, concurrent with marketing approval, the 
regulatory authority may seek agreement from a sponsor to conduct Phase 4 (postmarketing) studies to gather additional information about safety (especially with long-term use or in diverse populations), benefits, and optimal use under field conditions. These studies could include, but would not be limited to, examining different dosages or schedules of administration than were tested in Phase 2 studies, use of the drug in other patient populations or at other stages of the disease, or use of the drug over a longer period of time.

\section{Placebo}

An inactive medical treatment-a chemically inert substance that has no specific pharmacological effect on the illness or condition being studied-given to participants in the control group of a clinical trial. Use of a placebo allows the effects of the experimental treatment given to the study group to be distinguished and enables investigators to learn whether it produces results. Use of a placebo can also help determine whether improvement and/or side effects may reflect the user's imagination or anticipation rather than the power of a drug.

\section{PREP}

Pre-exposure prophylaxis, the use of an antiviral drug taken prior to HIV exposure for prevention of HIV transmission. Examples of known effective uses of PREP are the provision of nevirapine, AZT (zidovudine, formerly called azidothymidine), and/or other drugs to prevent mother-to-childtransmission of HIV infection during pregnancy or childbirth. Clinical trials to evaluate the effectiveness of PREP to prevent sexual or IDU-related infection are currently underway. Postexposure prophylaxis (PEP), in which use of antiretroviral drugs is initiated soon after possible exposure to $\mathrm{HIV}$, is already employed in many health-care settings, and to prevent HIV infection following rape.

\section{(Principal) investigator}

An individual who actually conducts a clinical investigation (that is, the individual under whose immediate direction the test product is administered or dispensed to a study participant). If a trial is conducted by a team of individuals at a trial site, the investigator is the responsible leader of the team and may be called the principal investigator. A sponsor-investigator is an individual who both initiates and conducts a clinical trial, alone or with others, and under whose immediate direction the investigational product is administered or dispensed to a study participant.

\section{Pro-2000}

A candidate vaginal microbicide, developed by Indevus, currently in safety, acceptability, and efficacy trials. It is an entry-and-fusion inhibitor (napthalene sulphonate polymer) that binds to viruses and bacteria to prevent them from binding to and infecting healthy cells. It may protect against HIV, gonorrhea, and HSV. Its contraceptive efficacy is expected to be dose dependent.

\section{Protocol}

An explicit, detailed plan for a study, experiment, procedure, or test. The protocol defines question(s) to be answered and provides complete, specific details concerning procedures, selection of participants, assignment of participants to treatment groups, adherence, follow-up, and withdrawal. The protocol document describes the intervention, the activities to be undertaken, the groups to receive the intervention, and the roles and responsibilities of the investigators; it should also spell out the study's objectives, how the results will be measured, and the intent of the work.

\section{Randomization}

Assignment of participants in a trial to treatment groups according to some known probability distribution; a procedure or method for assigning treatments to participants or dividing participants into treatment groups by random allocation. Randomization is generally used to eliminate selection bias by researchers or participants, to ensure that the statistical analysis of data will be valid, and to create groups compa- 
rable with respect to all factors that could influence outcome.

\section{Savvy (C-31 G)}

A candidate vaginal microbicide, developed by Biosyn, currently in safety and efficacy trials; a surfactant (detergent) that breaks down the lipid membranes of enveloped viruses and bacteria. Savvy is expected to act as a contraceptive and may protect against HIV, chlamydia, and HSV.

\section{Standard operating procedures (SOPs)}

Standard operating procedures are clearly written descriptions of processes to be followed and particular tasks to be performed that have been standardized to ensure that they are followed or performed the same way each time they are undertaken. In clinical trials, SOPs are essential for ensuring that regulatory and organizational policy requirements are met, for training new personnel, and for managing workload; they ensure that the site has consistent processes that meet or exceed regulatory and good clinical practice standards, that all employees are familiar with the processes, and that processes are reviewed and updated on a regular basis.

\section{Sponsor}

An individual, company, institution, or organization that takes responsibility for the initiation, management, and/or financing of a clinical trial.

\section{Tenofovir}

An FDA-approved antiretroviral drug (tenofovir disoproxil fumarate), marketed under the name Viread ${ }^{\mathrm{TM}}$, that is now widely used in combination with other antiretrovirals to treat HIV infection. Tenofovir is a nucleotide analog reverse transcriptase inhibitor (NRTI); it blocks the functioning of HIV reverse transcriptase, an enzyme that HIV requires to multiply in the human body. Tenofovir is not a cure for HIV, but it has been shown to reduce the HIV viral load among many patients when it is used as part of combination therapy. Currently, tenofovir is undergoing safety and effectiveness trials as pre-exposure prophylaxis (see PREP) - a once-a-day pill that may reduce the likelihood of acquiring HIV infection.

\section{Therapeutic misconception}

A trial participant's distorted understanding of the benefits and risks of participating in clinical research, that is, confusion between research and treatment; a study participant's belief that he or she will experience personally a direct therapeutic benefit from the research. Even after explanation of the experimental nature of the research, trial participants may not understand that the test product could be ineffective and fail to protect them, and that the placebo offers no protection. The therapeutic misconception results from participants' confusing the research setting with the care setting, such that they believe the researchers are "treating" them for their health needs.

\section{Vaccine}

A biological product that contains an antigen, generally made from an infectious agent or its components - a virus, bacterium, or other microorganism - that is killed (inactive) or live-attenuated (active, although weakened). Vaccines may be biochemically or genetically synthesized. A vaccine is designed to trigger the immune system to respond to a disease antigen and stimulate the production of antibodies to protect against the specific disease, and thus confer immunity against the disease that the organisms cause, for a period of time or permanently.

\section{Voluntary counseling and testing (VCT)} The process by which an individual undergoes confidential counseling to enable the individual to make an informed choice about learning his or her HIV status and to take appropriate action. If the individual chooses to take the HIV test, VCT enables confidential testing. The voluntary nature of VCT is one of its underlying principles. 
Appendices 
Appendix 1: Workshop Agenda

\section{Workshop on Informed Consent in HIV Prevention Trials}

Cohosted by the Population Council and Family Health International Population Council, New York, NY

16-18 May 2005

\section{Agenda}

Monday, 16 May

8:30-9:00 Continental Breakfast and Registration

9:00-9:15 Welcome

9:15-9:30 Review of the Agenda and Workshop Goals

9:30-10:45 Setting the Stage

An Overview of the Challenges Implicit in Facilitating Informed Decisionmaking among Research Participants in the Developing World (20 minutes)

Informed Consent in Context (20 minutes)

Informed Consent Challenges: Institutional Requirements (20 minutes)

Peter Donaldson

President, Population Council

Barbara Friedland

Population Council

Moderator: Johannes van Dam

Population Council

Jerome Singh

Center for the AIDS Programme

of Research in South Africa

Kathleen MacQueen

Family Health International

Barbara Pennington

Pharmaceutical Product Development

Discussion (15 minutes)

10:45-11:00

Break

$11: 00-12: 30$

\section{Current Informed Consent Processes and} Procedures

Informed Consent for HPTN 035 (20 minutes)

Informed Consent Process: The Botswana

Oral Tenofovir Prophylaxis Trial (20 minutes)

HSV-2/HIV Transmission Study: Recruitment and Informed Consent Issues with HIVdiscordant Couples (20 minutes)
Moderator/Discussant: Nancy Kass Johns Hopkins University

Cynthia Woodsong

Research Triangle Institute

Kata Chillag

US Centers for Disease Control and

Prevention

Andrew Mujugira

University of Washington,

Partners in Prevention

Discussion (30 minutes) 
$12: 30-1: 30$

$1: 30-3: 45$

$3: 45-4: 00$

4:00-5:00

5:00-7:00

\section{Lunch}

During lunch, those who are interested can view the Carraguard Phase 3 video and the MIRA trial video, which will be discussed tomorrow morning.

\section{Factors Influencing Decisionmaking}

Risk Perception and Decisionmaking (20 minutes)

The Impact of Participant Remuneration on Informed Consent (15 minutes)

Community Influence on Informed Consent (10 minutes)

The Informed Consent Advocate (10 minutes)

Discussion (25 minutes)

Break

Men in Microbicides Trials

Male Partner Consent for Microbicide Trials (10 minutes)

Male Involvement in Microbicide Trials (10 minutes)

Men in Microbicide Trials: Carraguard Couples Study (10 minutes)

Discussion (30 minutes)

\section{Reception}

There will be a reception for meeting participants and Population Council colleagues on the eighth floor.
Moderator: Martha Brady

Population Council

Julie Downs

Carnegie Mellon University

Keymanthri Moodley

University of Stellenbosch

Marge Chigwanda

UZ/UCSF Collaborative Research

Programme

John Attafuah

Visual Access, LTD

Moderator: Lori Heise

Global Campaign for Microbicides

Neelam Jogklekar

National AIDS Research Institute

Sicelo Gumede

Medical Research Council, South Africa

Supaporn Chaikummao

Thai Ministry of Public Health/US Centers

for Disease Control and Prevention

Collaboration 
Tuesday, 17 May

8:30-9:00

9:00-10:15

$10: 15-10: 30$

10:30-12:00

$12: 00-1: 00$

$1: 00-2: 30$

\section{Continental Breakfast}

Challenges in the Development and Implementation of the Informed Consent Process

IEC and the Informed Consent Process

(20 minutes)

The Costs of Informed Consent (20 minutes)

Discussion (20 minutes)

\section{Break}

Three Case Studies on Materials

Development

Carraguard Phase 3 Trial: Developing and Implementing a Video (20 minutes)

Challenges in the Development and Implementation of the Informed Consent Process: The MIRA Study (20 minutes)

AIDSVax Phase 3 Trial (20 minutes)

Discussion (30 minutes)

\section{Lunch}

During lunch, those who are interested can view the Partners in Prevention video a work-in-progress being developed for the HSV-2/HIV Couples study.

\section{Assessing Comprehension}

Checking for Levels of Competence (20 minutes)

\section{Three Case Studies on Assessing Comprehension}

Comprehension in a Microbicide Feasibility Study (15 minutes)

HPTN 035 Informed Consent Comprehension Assessment (15 minutes)

Assessing Comprehension of the Informed Consent in a Phase 3 Trial of Cellulose Sulfate (15 minutes)

Discussion (20 minutes)
Moderator: Barbara Friedland Population Council

Maggie Díaz

Reprolatina - Soluções Inovadoras em Saúde Reprodutiva

John Townsend

Population Council

Moderator: Barbara Friedland

Population Council

Alana de Kock

University of Cape Town

Mabitso Marumo

University of Limpopo, Medunsa

Sinazo Pato

Perinatal HIV Research Unit, Baragwanath Hospital

Punnee Pitisuttithum Mahidol University

Moderator: Kathleen MacQueen Family Health International

Elva Moser

Swift Consulting and Coaching Consortium

Neetha Morar

Medical Research Council, South Africa

Anne Coletti

Family Health International

Lut Van Damme

CONRAD 
$2: 30-2: 45$

2:45-4:00

4:00-4:45

4:45-5:00

5:00

Break

Monitoring and Evaluating the Informed Consent Process

Empirical Evidence on Improving Research Participants' Understanding (15 minutes)

In-depth Interviews to Evaluate the Informed Consent Process (15 minutes)

Informed Consent: What Should We Be Evaluating and Why? (20 minutes)

Discussion (25 minutes)

Summary and conclusion

Closing remarks

Meeting adjourns
Moderator: Jeremy Sugarman Johns Hopkins University

James Flory

University of Pennsylvania

Agnes Ssali Medical Research Council Programme on AIDS in Uganda/Uganda Virus

Research Initiative

Jeremy Sugarman

Johns Hopkins University

Elizabeth McGrory

Population Council Consultant

Barbara Friedland

Population Council

Wednesday, 18 May
8:30-9:00
Continental Breakfast

9:00-10:30

Learning about Learning

Speaker/Moderator: Elva Moser

Swift Consulting and Coaching

Consortium

10:30-10:45

10:45-1:00

1:00-1:45

$1: 45-2: 45$

$2: 45-3: 00$

3:00
Break

Communicating Complex Concepts

Lunch

Training Staff for Informed Consent Activities

Closing remarks

Meeting adjourns
Speaker/Moderator: Hillary Bracken Population Council Consultant

Speaker/Moderator: Cynthia Woodsong Research Triangle Institute

Barbara Friedland

Population Council 


\section{Appendix 2: List of Participants}

\author{
Arthur Allen \\ Quality Assurance Unit Manager \\ Population Council \\ Center for Biomedical Research \\ 1230 York Avenue \\ New York, NY 10021, USA \\ Tel: (212) 327-7188 \\ Fax: (212) 327-7678 \\ E-mail: aallen@popcouncil.org
}

\section{Sandra Arnold}

Vice President, Corporate Affairs

Population Council

One Dag Hammarskjold Plaza

New York, NY 10017, USA

Tel: (212) 339-0663

Fax: (212) 755-6052

E-mail: sarnold@popcouncil.org

John Attafuah

Chief Executive Officer

Virtual Access, Ltd.

6 Odono Street

North Kaneshie, DTD-ARW

Accra, Ghana

Tel: (233) 21-222-381

Fax: (233) 21-231-415

E-mail: jattafuah@tdftema.org johnattafuah@4u.com.gh

Judith Auerbach

Vice President

Public Policy and Program

Development

American Foundation for AIDS

Research

1828 L Street, NW, Suite 802

Washington, DC 20036, USA

Tel: (202) 331-8600

Fax: (202) 331-8606

E-mail: judy.auerbach@amfar.org

Julie Becker

Senior Director

Country and Regional Programmes

International AIDS Vaccine Initiative

110 William Street, 27th Floor

New York NY 10038-3901, USA

Tel: (212) 763-5465

Fax: (212) 847-1112

E-mail: jbecker@iavi.org
Kelly Blanchard

President

Ibis Reproductive Health

2 Brattle Square

Cambridge, MA 02138-3742, USA

Tel: (617) 349-0040

Fax: (617) 349-0041

E-mail: kblanchard@ibisreproductivehealth.org

\section{Hillary Bracken}

Consultant

c/o Population Council

One Dag Hammarskjold Plaza

New York, NY 10017, USA

Tel: (212) 339-0500

Fax: (212) 755-6052

E-mail: hbracken@gynuity.com

\section{Martha Brady}

Program Associate

Population Council

One Dag Hammarskjold Plaza

New York, NY 10017, USA

Tel: (212) 339-0618

Fax: (212) 755-6052

E-mail: mbrady@popcouncil.org

Patrick Brenny

Country Coordinator

UNAIDS

United Nations Building

12th Floor

Rajadamnem Nok Avenue

Bangkok 10200, Thailand

Tel: (66) 2-288-1882

Fax: (66) 2-280-1414

E-mail: patrick.brenny@un.or.th

\section{Marianne Callahan}

Deputy Director/Clinical Director CONRAD

Eastern Virginia Medical School 1611 North Kent Street,

Suite 806

Arlington, VA 22209, USA

Tel: (703) 524-4744

Fax: (703) 524-4770

E-mail: mcallahan@conrad.org
Supaporn Chaikummao

Clinical Research Specialist

Thai Ministry of Public Health/

US CDC Collaboration

Department of Disease Control

4th Floor, Building 7

Tivanon Road

Nonthaburi 11000 , Thailand

Tel: (66) 2-580-0669, ext. 464

(66) $1-850-4343$

Fax: (66) 2-580-0712

E-mail: SupapornC@tuc.or.th

Marge Chigwanda

Counseling Director

UZ-UCSF Collaborative

Research Programme

15 Phillips Avenue

Belgravia

Harare, Zimbabwe

Tel: (263) 4-91-241-699

(263) 4-706-540

Fax: (263) 4-704-897

(263) 4-725-038

E-mail: marge@uz-ucsf.co.zw

Kata Chillag

Behavioral Scientist

HIV Epidemiology Branch

US Centers for Disease Control and Prevention

1600 Clifton Road, NE, MS E-45

Atlanta, GA 30333, USA

Tel: (404) 639-0948

Fax: (404) 639-6127

E-mail: kchillag@cdc.gov

Anne Coletti

Senior Scientist

Family Health International

HIV Prevention Trials Network

12 Madison Street

Medford, MA 02155, USA

Tel: (781) 874-1208

Fax: (781) 874-1195

E-mail: AColetti@fhi.org 
Paul Coplan

Director of Clinical and

Regulatory Affairs

International Partnership for

Microbicides

1010 Wayne Avenue, Suite 1450

Silver Spring, MD 20910, USA

Tel: (301) 608-2221

Fax: (202) 608-2241

E-mail:

PCoplan@ipm-microbicides.org

\section{Brittany Dawson}

HHS Emerging Leaders Program

National Institute for Child Health and Human Development

Demographic and Behavioral

Sciences Branch

Executive Building

6100 Executive Boulevard, MSC 7510

Rockville, MD 20892-7510, USA

Tel: (301) 435-6986

Fax: (301) 496-0962

E-mail: brittany.dawson@hhs.gov

Alana de Kock

Social Science Investigator

University of Cape Town

School of Public Health and

Family Medicine

Infectious Disease Epidemiology Unit

Falmouth Building

Anzio Road, Observatory 7925

Cape Town, South Africa

Tel: (27) 21-406-6716

Fax: (27) 21-406-6308

E-mail: dekock@cormack.uct.ac.za

Maggie Díaz

Presidenta

Reprolatina - Soluções Inovadoras em Saúde Sexual Reprodutiva

Rua Maria Teresa Días da Silva

740 Cidade Universitaria

Campinas

São Paolo CEP 13084-190, Brazil

Tel: (55) 19-3289-1735

Fax: (55) 19-3289-1736

E-mail: mdiaz@reprolatina.org.br

\section{Peter Donaldson}

President

Population Council

One Dag Hammarskjold Plaza

New York, NY 10017, USA

Tel: (212) 3390686

Fax: (212) 755-6052

E-mail: pdonaldson@popcouncil.org
Julie Downs

Director

Center for Risk Perception and Communication

Carnegie Mellon University

Department of Social and

Decision Sciences

Porter Hall 208

Pittsburgh, PA 15213-3890, USA

Tel: (412) 268-6937

E-mail: downs@andrew.cmu.edu

Gina Duclayan

Senior Writer/Editor

Population Council

One Dag Hammarskjold Plaza

New York, NY 10017, USA

Tel: (212) 339-0510

Fax: (212) 755-6052

E-mail: gduclayan@popcouncil.org

Suzie Elliott

Public Information Specialist

Population Council

One Dag Hammarskjold Plaza

New York, NY 10017, USA

Tel: (212) 339-0520

Fax: (212) 755-6052

E-mail: selliott@popcouncil.org

Pat Fast

Director

Medical Affairs, Research and

Development

International AIDS Vaccine Initiative

110 William Street, 27th Floor

New York, NY 10038-3901, USA

Tel: (212) 847-1068

Fax: (212) 847-1112

E-mail: pfast@iavi.org

James Flory

Medical Student

University of Pennsylvania

Medical School

Stemmler Hall, 3450 Hamilton Walk

Mailbox 369

Philadelphia, PA 19104-6087, USA

Tel: (301) 452-4288

E-mail: jflory@mail.med.upenn.edu

\section{Barbara Friedland}

Program Manager

Population Council

One Dag Hammarskjold Plaza

New York, NY 10017 USA

Tel: (212) 339-0629

Fax: (212) 755-6052

E-mail: bfriedland@popcouncil.org
Gregg Gonsalves

Director of Treatment and

Prevention Advocacy

Gay Men's Health Crisis

119 West 24th Street

New York, NY 10011, USA

Tel: (212) 367-1169

Fax: (212) 367-1235

E-mail: greggg@gmhc.org

Sicelo Gumede

Behavioral Coordinator

HIV Prevention Research Unit

Medical Research Council of

South Africa

123 Jan Hofmeyer Drive

Westville 3630, South Africa

Tel: (27) 31-242-3600

Fax: (27) 31-242-3800

E-mail: Sicelo.Gumede@mrc.ac.za

Lori Heise

Director

Global Campaign for Microbicides

c/o PATH

1800 K Street, NW

Washington, DC 20006, USA

Tel: (202) 454-5028

Fax: (202) 457-1466

E-mail: Iheise@path-dc.org

Paul Hewett

Associate

Population Counci

One Dag Hammarskjold Plaza

New York, NY 10016, USA

Tel: (212) 339-0683

Fax: (212) 755-6052

E-mail: phewett@popcouncil.org

Anrudh Jain

Vice President

International Programs Division

Population Council

One Dag Hammarskjold Plaza

New York, NY 10017, USA

Tel: (212) 339-0639

Fax: (212) 755-6052

E-mail: ajain@popcouncil.org

Neelam Sanjay Joglekar

Behavioural Scientist

National AIDS Research Institute

73, G-block, MIDC, Bhosari

Pune, Maharashtra 411026, India

Tel: (91) 20-2712-1343

Fax: (91) 20-2712-1071

E-mail: joglekarneelam@yahoo.com 
Elof Johansson

Vice President

Center for Biomedical Research,

Population Council

1230 York Avenue

New York, NY 10021, USA

Tel: (212) 327-8717

Fax: (212) 327-7678

E-mail: ejohansson@popcouncil.org

Heidi Jones

Staff Program Associate

Population Council

One Dag Hammarskjold Plaza

New York, NY 10017, USA

Tel: (212) 339-0658

Fax: (212) 755-6052

E-mail: hjones@popcouncil.org

Marvin Kalt

Senior Advisor for Special

Partnership Projects

$\mathrm{NIH} /$ Bill \& Melinda Gates Foundation

Post Office Box 23350

Seattle, WA 98102, USA

Tel: (206) 709-3396

Fax: (206) 709-3170

E-mail: marvink@gatesfoundation.org

Nancy Kass

The Phoebe R. Berman Professor of Bioethics and Public Health

Johns Hopkins University

Phoebe R. Berman Bioethics Institute

Johns Hopkins Bloomberg School of Public Health

624 North Broadway

Baltimore, MD 21205, USA

Tel: (410) 955-0310

Fax: (410) 614-9567

E-mail: nkass@jhsph.edu

\section{Cissy Kityo}

c/o International AIDS Vaccine Initiative

110 William Street, 27th Floor

New York, NY 10038-3901, USA

Tel: (212) 847-1068

Fax: (212) 847-1112
Beryl Koblin

Head

Laboratory of Infectious Disease

Prevention

Project Achieve

New York Blood Center

310 East 67 th Street

New York, NY 10021, USA

Tel: (212) 570-3105

Fax: (212) 861-5873

E-mail: bkoblin@nybloodcenter.org

Kathleen MacQueen

Family Health International

Post Office Box 13950

Research Triangle Park, NC 27709, USA

Tel: (919) 544-7038

Fax: (919) 544-7259

E-mail: KMacQueen@fhi.org

Judith M. Manning

Senior Biomedical Research Advisor

United States Agency for

International Development

Office of Population and

Reproductive Health

1300 Pennsylvania Ave, NW

Washington, DC 20523-3601, USA

Tel: (202) 712-1232

Fax: (202) 216-3404

E-mail: jmanning@usaid.gov

Mabitso Marumo

Senior Counselor

Setshaba Research Center

2088 Block H

Soshanguve 0152, South Africa

Tel: (27) 12-799-2422

Fax: (27) 12-799-2685

E-mail: bitso@setshaba.org.za

L. Camille Massey

Advisor

Country and Regional Programmes International AIDS Vaccine Initiative 110 William Street, 27th Floor

New York, NY 10038-3901, USA

Tel: (917) 513-4922 (mobile)

(212) 847-1047 (direct line)

Fax: (212) 847-1112

E-mail: CMassey@iavi.org

\section{Elizabeth McGrory}

Consultant

24 Second Avenue

Nyack, NY 10960, USA

Tel: (845) 353-3973

Fax: (845) 353-3973

E-mail: emcgrory@optonline.net
Linda K. McNeil

Associate Director

Research Operations,

Clinical Research

Family Health International

Post Office Box 13950

Research Triangle Park, NC 27709, USA

Tel: (919) 544-7040 ext. 319

Fax: (919) 544-7261

E-mail: Imcneil@fhi.org

Vuyelwa Mehlomakulu

Study Coordinator

University of Cape Town

Faculty of Health and Sciences

School of Public Health

Falmouth Building, 5th Floor

Anzio Road Observatory, 7925

Cape Town, South Africa

Tel: (27) 21-633-6599

Fax: (27) 21-637-7389

E-mail: vuyelwa@cormack.uct.ac.za

Keymanthri Moodley

Associate Professor

University of Stellenbosch

Centre for Applied Ethics and

Faculty of Health Sciences

Bioethics Unit-Tygerberg Division

Post Office Box 19063

Tygerberg 7505, South Africa

Tel: (27) 21-938-9600 or

(27) 21-938-9182

E-mail: KM@sun.ac.za

Neetha Morar

Senior Scientist and

Research Manager

HIV Prevention Unit

Medical Research Council of

South Africa

123 Jan Hofmeyer Drive

Westville 3630 , South Africa

Tel: (27) 31-242-3630/3600

(27) 82-447-0389 (mobile)

Fax: (27) 31-242-3800

E-mail: Neetha.Morar@mrc.ac.za

Elva A. Moser

President

Swift Coaching and Consulting

Consortium

55 Park Avenue, Suite 1

Bloomfield, NJ 07003, USA

Tel: (973) 743-4025

(973) 271-1768 (mobile)

Fax: (973) 743-4094

E-mail: El.Moser@verizon.net 
Andrew Mujugira

Partners in Prevention

University of Washington

Post Office Box 784404

Sandton 2146, South Africa

Tel: (27) 73-638-8024

Fax: (27) 11-325-4548

E-mail: mujugira@u.washington.edu

\section{Lulu Oguda}

Clinical/Regulatory Manager

Africa Region

International Partnership for

Microbicides

1010 Wayne Avenue, Suite \# 1450

Silver Spring, MD 20910, USA

Tel: (301) 608-2221

Fax: (202) 608-2241

E-mail:

loguda@ipm-microbicides.org

\section{Sinazo Pato}

Community Liaison Officer

MIRA Study

Perinatal HIV Research Unit

Box 114

9th floor, Nurses Home

Baragwanath Hospital

Soweto, Johannesburg

Diepkloof 1867, South Africa

Tel: (27) 11-989-9819

Fax: (27) 11-989-9820

E-mail: patos@hivsa.com

\section{Barbara Pennington}

Training Manager

Pharmaceutical Product

Development (PPD)

1615 Canady Road

Wilmington, NC 28411, USA

Tel: (910) 772-6893

E-mail:

barbara.pennington@wilm.ppdi.com

Punnee Pitisuttithum

Associate Professor

Chief, Clinical Infectious

Disease Unit

Mahidol University

Faculty of Tropical Medicine

Vaccine Trial Centre

420/6 Rajvithi Road, Rajthevee

Bangkok 10400, Thailand

Tel: (662) 6-435-599

Fax: (662) 6-435-598

E-mail: tmppt@mahidol.ac.th
Saumya Ramarao

Program Associate

Population Council

One Dag Hammarskjold Plaza

New York, NY 10017, USA

Tel: (212) 339-0603

Fax: (212) 755-6052

E-mail: sramarao@popcouncil.org

Renee Ridzon

Senior Program Officer

HIV, TB and Reproductive Health

Bill \& Melinda Gates Foundation

Post Office Box 23350

Seattle, WA 98102, USA

Tel: (206) 709-3383

Fax: (206) 709-3170

E-mail: reneer@gatesfoundation.org

Diane Rubino

Communications and Media Specialist

Population Council

One Dag Hammarskjold Plaza

New York, NY 10017, USA

Tel: (212) 339-0617

Fax: (212) 755-6052

E-mail: drubino@popcouncil.org

Monica S. Ruiz

Behavioral Scientist

Prevention Sciences Branch

Division of AIDS

National Institute of Allergy and Infectious Diseases

National Institutes of Health

6700B Rockledge Drive

Bethesda, MD 20892-7628, USA

Tel: (301) 435-3757

Fax: (301) 496-8530

E-mail: mruiz@niaid.nih.gov

Jim Sailer

Senior Director

Corporate Affairs

Population Council

One Dag Hammarskjold Plaza

New York, NY 10017, USA

Tel: (212) 339-0697

Fax: (212) 755-6052

E-mail: jsailer@popcouncil.org
Katie Schenk

Program Associate

Population Council-Horizons Project

4301 Connecticut Avenue, NW,

Suite 280

Washington, DC 20008, USA

Tel: (202) 237-9431

Fax: (202) 237-8410

E-mail: kschenk@pcdc.org

Jerome Amir Singh

Head

Bioethics and Health Law Programme

Centre for the AIDS Programme

of Research in South Africa

Doris Duke Medical Research Institute

Nelson R. Mandela School of Medicine

University of KwaZulu-Natal

Private Bag X7

Congella 4013, South Africa

Tel: (27) 031-260-4664/260-4555

Fax: (27) 031-260-4566

E-mail: singhj9@ukzn.ac.za jerome.singh@utoronto.ca

Stephanie Skoler

Study Manager

Microbicides Project

Population Council

Center for Biomedical Research

1230 York Avenue

New York, NY 10021, USA

Tel: (212) 327-7003

Fax: (212) 327-7678

E-mail: sskoler@popcouncil.org

Harris Solomon

Biomedical Research Fellow

United States Agency for

International Development

Bureau for Global Health, 3.6-158

Office of Population and

Reproductive Health

1300 Pennsylvania Avenue, NW

Washington, DC 20523-3601, USA

Tel: (202) 712-1841

Fax: (202) 216-3404

E-mail: hsolomon@usaid.gov

Agnes Ssali

Social Scientist

Medical Research Council

Programme on AIDS in Uganda/

Uganda Virus Research Institute

Post Office Box 49

Entebbe, Kampala, Uganda

Tel: (256) 481-21211

Fax: (256) 481-21082

E-mail: agnes.ssali@mrcuganda.org 
Jeremy Sugarman

Harvey M. Meyerhoff Professor of

Bioethics and Medicine

Johns Hopkins University

Phoebe R. Berman Bioethics

Institute and Department of

Medicine

Hampton House 351

624 North Broadway

Baltimore, MD 21205, USA

Tel: (410) 955-3119

Fax: (410) 614-9567

E-mail: jsugarm1@jhmi.edu

John Townsend

Program Director

Population Council-Frontiers

Program

4301 Connecticut Avenue, NW,

Suite 280

Washington, DC 20008, USA

Tel: (202) 237-9400

Fax: (202) 237-8410

E-mail: jtownsend@pcdc.org

Johannes van Dam

Director

Reproductive Health

Population Council

One Dag Hammarskjold Plaza

New York, NY 10017, USA

Tel: (212) 339-0623

Fax: (212) 755-6052

E-mail: jvandam@popcouncil.org

Lut Van Damme

Program Director

Reproductive Health

CONRAD

Eastern Virginia Medical School 1611 North Kent Street, Suite 806

Arlington, VA 22209, USA

Tel: (703) 524-4744

Fax: (703) 524-4770

E-mail: Ivandamme@conrad.org
Janneke van de Wijgert

Director

Prevention Research

International Antiviral Therapy

Evaluation Center

Academic Medical Center

Pietersbergweg 9

Amsterdam 1105 BM,

The Netherlands

Tel: (31) 20-314-9355

Fax: (31) 20-314-9399

E-mail: j.vandewijgert@iatec.com

Mitchell Warren

Executive Director

AIDS Vaccine Advocacy Coalition

101 West 23rd Street, Suite 2227

New York, NY 10011, USA

Tel: (212) 367-1084

Fax: (646) 365-3452

E-mail: mitchell@avac.org

Deborah Watson-Jones

HSV Project Manager and London

School of Hygiene and Tropical

Medicine

Team Leader for the NIMR/AMREF/

LSHTM Collaborative Projects

African Medical and Research

Foundation

Post Office Box 1482

Mwanza, Tanzania

Tel: (255) 28-250-0220

(255) 74-405-6066 (mobile)

Fax: (255) 28-250-0742

E-mail: DebbyW@amrefmza.org

Sydney West

Country Preparedness and

Site Manager

International Partnership for

Microbicides

1010 Wayne Avenue, Suite 1450

Silver Spring, MD 20910, USA

Tel: (301) 608-2221

Fax: (202) 608-2241

E-mail: Swest@ipm-microbicides.org
Nela (M.M.) Williams

Study Coordinator

Setshaba Research Center

2088 Block H

Soshanguve 0152, South Africa

Tel: (27) 12-799-2422

Fax: (27) 12-799-2685

E-mail: nela@setshaba.org.za

Beverly Winikoff

President

Gynuity Health Projects

15 East 26th Street, Suite 1609

New York, NY 10010, USA

Tel: (212) 448-1230

Fax: (212) 448-1260

E-mail: bwinikoff@gynuity.org

Cynthia Woodsong

Senior Scientist

Center for Global Health

Research Triangle Institute International

Post Office 12194

Research Triangle Park, NC 27709, USA

Tel: (919) 541-6643

E-mail: cwoodsong@rti.org

Serena Wright

Scientific Coordinator

University of California,

San Francisco

74 New Montgomery Street, Suite 600

San Francisco, CA 94105, USA

Tel: (415) 597-8185

Fax: (415) 597-9300

E-mail: swright@psg.ucsf.edu 


\section{Population Council}

One Dag Hammarskjold Plaza

New York, NY 10017 USA

Telephone: (212) 339-0500

Fax: (212) 755-6052

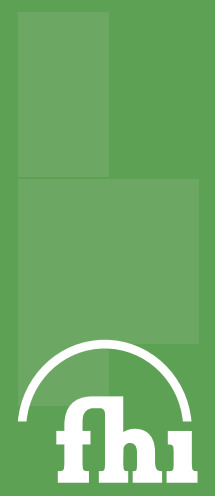

Family Health International

Post Office Box 13950

Research Triangle Park, NC 27709 USA

Telephone: (919) 544-7040

Fax: (919) 544-7261

2101 Wilson Boulevard, Suite 700

Arlington, VA 22201 USA

Telephone: (703) 516-9779

Fax: (703) 516-9781 